\title{
Review
}

\section{Protein import machineries in endosymbiotic organelles}

\author{
M. Balsera ${ }^{a, b, c, ~ d, ~ *, ~ J . ~ S o l l ~}{ }^{a, b}$ and B. Bölter ${ }^{a, b}$ \\ ${ }^{a}$ Departement Biologie I-Botanik, Ludwig-Maximilians-Universität, Großhadernerstr. 2-4, 82152 \\ Planegg-Martinsried (Germany) \\ ${ }^{b}$ Munich Center for Integrated Protein Science CiPSM, Ludwig-Maximilians-Universität, \\ Feodor-Lynen-Strasse 25, D-81377 Munich (Germany) \\ 'Departamento de Estrés Abiótico, Instituto de Recursos Naturales y Agrobiología de Salamanca \\ (IRNASA-CSIC), Apdo. 257, 37071 Salamanca (Spain) \\ ${ }^{\mathrm{d}}$ Present address: Department of Structural Biology, Paul Scherrer Institute, 5232 Villigen PSI (Switzerland), \\ Fax:+41(0)563105288; e-mail: monica.balsera@psi.ch
}

Received 08 October 2008; received after revision 06 January 2009; accepted 13 January 2009

Online First 6 February 2009

\begin{abstract}
Chloroplast and mitochondria, the two organelles with an accepted endosymbiotic origin, have developed multiple translocation pathways to ensure the subcellular allocation of proteins synthesized by cytosolic ribosomes, and to guarantee their assembly into functional complexes in coordination also with organellar-encoded subunits. The evolution
\end{abstract}

of different protein import machineries was thus essential for the development of these two organelles within cells. A general overview of the translocation machineries in chloroplast and mitochondrial membranes involved in targeting and import of nuclearencoded proteins, with special focus on plant cells where the two organelles coexist, is expounded.

Keywords. Protein translocation, mitochondria, chloroplasts, thylakoids, dual-targeting, endosymbiotic organelles.

\section{Endosymbiosis and the plant cell}

It is widely accepted that mitochondria, found in eukaryotic cells, and plastids, just in plant cells, are organelles of endosymbiotic origin [1]. Two independent endosymbiotic events gave rise to the evolution of these organelles in a plant cell. First, mitochondria evolved from a single endosymbiotic event between a host cell and an aerobic $\alpha$-proteobacterium. As a consequence, a diversity of heterotrophic eukaryotic lineages emerged [2]. Later, plastids were incorporated from a free-living photosynthetic prokaryote, an ancestor of contemporary cyanobacteria,

* Corresponding author. which was engulfed by a heterotrophic eukaryotic host that already contained mitochondria. The primary endosymbiotic event in plastid evolution gave rise to glaucophyta, rhodophyta and viridiplantae lineages [3]. Subsequent endosymbiotic events in plastid evolution have occurred [4].

With time, the majority of the genetic information from the endosymbionts was lost or transferred to the nucleus of the host cell, though some amount of information is still retained by the organelles, thus functioning as a semiautonomous system [5]. Because of the gene relocation in the host cell, several mechanisms were developed to re-target and efficiently transport the proteins acting in the organelles but now expressed in the host cytosol. Some of these machineries were adapted from bacteria; others show 


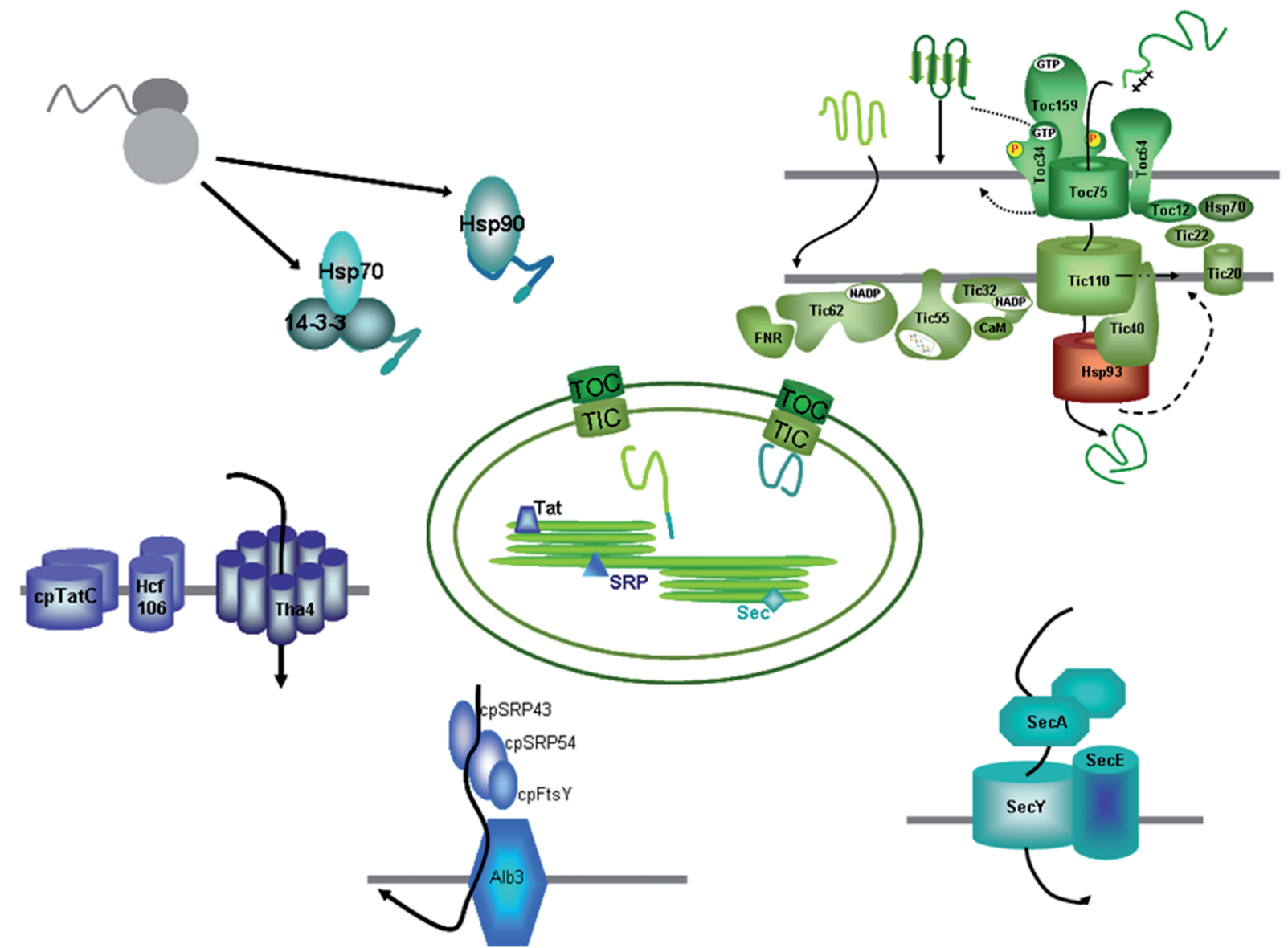

Figure 1. Overview of chloroplast translocation pathways. Indicated are the targeting pathways in the cytosol and all translocases present in chloroplast membranes. Complexes and their respective components are color coded (for easier identification). For details on composition, function and regulation please refer to the text.

no apparent homology to any bacterial secretion system but were newly developed, even though some constituents are of prokaryotic origin $[6,7]$. In any case, all of them follow certain general principles [8]. With the exception of the Tat transport pathway in thylakoids (see below), the substrate has to be unfolded or loosely folded in order to be translocated. The substrates, in a complex with chaperones in an import-competent state (post-translational import) or nascent in ribosomes (co-translational import), bind to membrane receptors and are transferred to the membrane-embedded protein import channels. Once there, the substrates completely cross the membrane with the assistance of chaperones on the trans side or are laterally transferred into the lipid bilayer. Unlike the case in other eukaryotic systems, plant cytosolic proteins destined for the mitochondrion must be distinguished from those destined for the plastid. Moreover, given the presence of plastids in plant cells, it is not surprising that plant mitochondria have specific features, uncommon in other eukaryotes, to ensure their integration and communication within the cell [9]. Herein we present a general overview of the translocation machineries in chloroplast and mitochondrial membranes involved in targeting and import of nuclear-encoded proteins, with special focus on plant cells where the two organelles coexist.

\section{Protein import in chloroplasts}

Most of the work in plastid-protein import has been carried out in chloroplasts, the most abundant type of plastids where photosynthesis occurs. It is believed that other plastids do contain identical sorting systems at the envelope level [10-12]. During the last years, one general import pathway in chloroplast envelopes has been described, constituted by the translocons at the outer and the inner envelope of chloroplasts (TOC and TIC, respectively) (Fig. 1). With the progress in plant genome information, gene multifamilies were recognized for some components of the envelope translocons. 


\section{Chloroplastic transit peptides}

The majority of nuclear encoded proteins destined for an interior chloroplast compartment comprise an $\mathrm{N}$ terminal transit peptide (TP), which is cleaved off by the stromal processing peptidase (SPP) during/after import $[13,14]$. In the early days of protein import research, people expected TPs to contain definite, clear motifs or structural features to ensure specific targeting and especially to avoid mistargeting to other organelles. Much to our surprise, it was found that TPs are heterogeneous in sequence and seem to be mostly unstructured $[13,14]$. They vary in length $(20-150$ amino acids) and show no sequence conservation. The only general features are the lack of acidic residues, resulting in an overall positive charge, and the presence of several hydroxylated amino acids, especially serine. In these aspects, they resemble mitochondrial targeting sequences (see below). However, in contrast to mitochondrial targeting signals, chloroplast TPs do not adopt a secondary structure in aqueous solution [15]. Von Heijne and Nishikawa even proposed that TP features result in a "perfect random coil" [16]. This lack of secondary structure is supposed to play an important role in the recruitment of cytosolic factors upon completion of translation [17, 18]. For some TPs it has been demonstrated that they acquire a typical structure upon contact with the lipid environment of the chloroplast outer envelope [19, 20], which has a unique composition clearly distinguishing it from the outer mitochondrial membrane [14]. Thus, it could be speculated that only upon interaction with the outer envelope-specific galactolipids do TPs adopt a secondary structure which then furthers the import process [21]. Very recently, Lee et al. [22] conducted a detailed study using hierarchical clustering to define certain motives within TPs and so far, they could assign several chloroplast preproteins to seven different groups. Some TPs, however, still do not fit into any of the established groups, so that the authors speculate about there being additional criteria not yet recognized.

\section{Moving from the cytosol to chloroplasts: Precursor protein delivery}

As preproteins emerge from the translating ribosome into the cytosol, they encounter a molecular crowded environment where they need to be protected from misfolding/aggregation. Additionally, it is necessary to maintain preproteins in an import competent state, i. e. unfolded and extended. Chloroplast TPs comprise high affinity binding sites for Hsp70 proteins [18, 23], which generally bind to unfolded polypeptides, though deletion of these motifs does not affect translocation in vitro $[24,25]$. Besides keeping preproteins in an import favorable conformation, cyto- solic components have been shown to be involved in the import process itself. Several plastid TPs comprise a binding motif for 14-3-3 proteins [17], known to mediate protein-protein interactions. These proteins specifically recognize phosphorylated residues within TPs [26,27] and together with Hsp70 build up a cytosolic guidance complex that escorts preproteins to chloroplasts only, since mitochondrial targeting sequences are not recognized by 14-3-3 proteins. Recently, an additional cytosolic system has been proposed: some preproteins have been shown to interact with Hsp90, rather than with Hsp70/14-3-3 [28]. These Hsp90 associated precursors first interact with the dynamically associated receptor Toc64 (see below) via its cytosolic tetratricopeptide repeat (TPR) domain and passes its cargo on to Toc34. Toc64 deletion mutants failed to exhibit any effects in growth or import behavior, indicating that the first step of recognition at the chloroplast surface involving Toc64 can be bypassed and the precursor, even when bound to Hsp90, can be accepted by Toc34 directly $[29,30]$. Thus, the pathway via Toc64 seems to represent a mechanism which renders in vivo import more efficient but is not absolutely essential.

\section{Import machinery at the outer envelope membrane of chloroplasts: the TOC complex}

The subunits that compose the TOC and the TIC complexes are named according to their molecular weight. The TOC complex is composed of a channel protein (Toc75), two GTPase receptors (Toc159 and Toc34) and two dynamically-associated components (Toc64 and Toc12) [31]. The protein import channel Toc75 is a highly conserved $\beta$-barrel protein evolutionarily related to Omp85, involved in the integration of proteins into the bacterial outer membrane in Gramnegative bacteria, and to the mitochondrial outer membrane protein Sam50/Tob55 family (see below) $[32,33]$. Recently, a high resolution structure has been obtained for a member of the Omp85 superfamily, providing a general insight into the mechanism of the system [34]. The protein is composed of two domains: the $\mathrm{N}$-terminal cytosolic region functions in recognition and as a complex assembly unit; the $\mathrm{C}$-terminal membrane-embedded region forms the $\beta$-barrel-type protein-channel, itself modulated by the $\mathrm{N}$-terminal region [35, 36]. In the Arabidopsis genome there are four Toc75 homologues: atToc75-I (a pseudogene), atToc75-III, atToc75-IV and atToc75-V, named according to the chromosome where they are encoded. AtToc75-III - the ortholog to Toc75 protein in Pisum sativum - is essential for the viability of plants from the embryonic stage, whereas atToc75-IV has a role during growth in the dark [37]. AtToc75-V, also known as OEP80, is the closer relative to the bacterial 
Omp85 family and might have a more specialized role in biogenesis of a relatively small subset of proteins [38]. A multigene Toc75 family is also found in Physcomitrella patens, whereas in green algae just two isoforms are recognized, one related to atToc75-III/IV and another to atToc75-V [39]. Red algae lack the at Toc75-V isoform and the only Toc75 sequence is related to atToc75-III/IV (unpublished data).

Toc34 is the major preprotein receptor of the Toc complex. It is anchored into the membrane by one transmembrane helix at the $\mathrm{C}$-terminus and exposes a large GTPase domain to the cytosol [40-42]. Two Toc34 isoforms are found in Arabidopsis, atToc34 and atToc33. Although highly similar in sequence $(60 \%$ identity), they show different properties, e. g. atToc33, but not atToc34, can be specifically phosphorylated $[43,44]$, and they display different tissue distribution in the plant. Whereas atToc33 is mainly expressed in photosynthetic tissues, atToc34 is the dominant isoform in roots. Nevertheless, analysis of mutant plants shows that at least the atToc33 isoform is replaceable by the other [45], and both participate in the translocation of proteins into plastids. The cytosolic GTPase domain in Toc34 is evolutionarily related to that found in Toc159, and belongs to the septin family of GTPases [46].

The sequence of the members of the Toc159 family has a modular architecture: a large $\mathrm{C}$-terminal membrane-anchored (M) domain, a cytosolic GTPase (G) domain and an N-terminal acidic (A) domain of unknown function whose length is reduced in the shorter versions of the Toc159 family [47]. Four orthologs (atToc159, atToc132, atToc120 and atToc90) form the Toc159 family in Arabidopsis. Many studies have related each of these isoforms with Toc75, pointing to a participation for all of the isoforms in the import process. Phylogenetically, they can be divided into three subfamilies: Toc159, Toc132/120 and Toc90 [47]. Functionally, they participate in at least two different import pathways. Whereas Toc159 and Toc 90 seem to play a significant role in the import of photosynthetic proteins in green tissues, Toc132/ Toc120 are important for import of essential housekeeping proteins, especially in non-green tissues [47, 48]. Reverse genetic studies have shown a functional redundancy between Toc132 and Toc120 [48]. Toc90 may have an accessory role in import. Moreover, their associations to Toc34 isoforms seem to respond specifically to functional demands: atToc33 associates preferably to atToc159 and atToc34 to atToc132/ atToc120 [48]. Several isoforms of Toc34 or Toc159 that fall into the category of the atToc132/atToc120 subfamily are also found in Physcomitrella (Fig. 2), as previously found in green algae [39]. Three sequences in Physcomitrella belong to the Toc34 family [39], but they diverged before the atToc34 and atToc33 branch (Fig. 2). Interestingly, just one copy of Toc34 is found in rice and Chlamydomonas [39]. Two homologous sequences to Toc159/Toc34 are found in red algae that phylogenetically seem to be closer to the Toc34 receptor type (Fig. 2). No bacterial or eukaryotic proteins are related to Toc159/Toc34 receptors [39], and this suggests that they appeared during evolution as a consequence of the development of chloroplasts, and that their specialization came with the evolution of vascular plants.

The third receptor, Toc64, has an N-terminal transmembrane anchor, a central amidase region, and a dicarboxylate clamp-type TPR domain at its Cterminus. It may act at both sides of the membrane, exposing the amidase region to the intermembrane space (IMS) and the TPR domain to the cytosol for specific interaction with cytosolic chaperones $[49,50]$. The Toc64 family is composed of three isoforms in Arabidopsis (named according to the chromosome where they are encoded), atToc64-III, atToc64-IV and atToc64-I, but only atToc64-III participates in the import process in chloroplasts in association with Toc75 [51]. AtToc64-V is a mitochondrial protein also known as atOM64 [51] (see below). AtToc64-I, or atAMI1, is a soluble cytosolic protein. Recently, it has been proposed that Toc64 might not be strictly required for the efficient import of proteins into chloroplasts [29, 30], but may allow an efficient distribution of the precursor proteins within the cell [31]. No orthologs of atToc64-III are found outside land plants [39]. Toc12 contains a highly conserved DNA-J domain that is placed in the IMS of the envelopes, where it associates with the amidase module of Toc64 and Tic22 [52]. In the IMS it recruits a yet uncharacterized Hsp70 and activates its ATPase activity. Toc12 is anchored to the outer envelope membrane by a short hydrophobic motif at the Nterminus. Although longer in sequence, the Arabidopsis protein At1 g80920 might be related to Toc12 in pea. Similar proteins are found as well in Physcomitrella and rice, suggesting that Toc12 might be found exclusively in land plants.

\section{Models of protein import through the TOC complex}

Based on specific energy requirements, protein import in chloroplasts has been initially divided into three distinct steps/stages [53, 54]: (a) reversible binding to the chloroplast surface, which is independent of nucleotides; (b) stable binding/insertion at $\leq 100 \mu \mathrm{M}$ ATP in the presence of GTP [55]. This intermediate step has very recently been analyzed in more detail and three distinct sub-stages have been defined [56]; (c) translocation and processing that requires $\geq 100$ $\mu \mathrm{M}$ ATP $[57,58]$. The recognition of preproteins by 


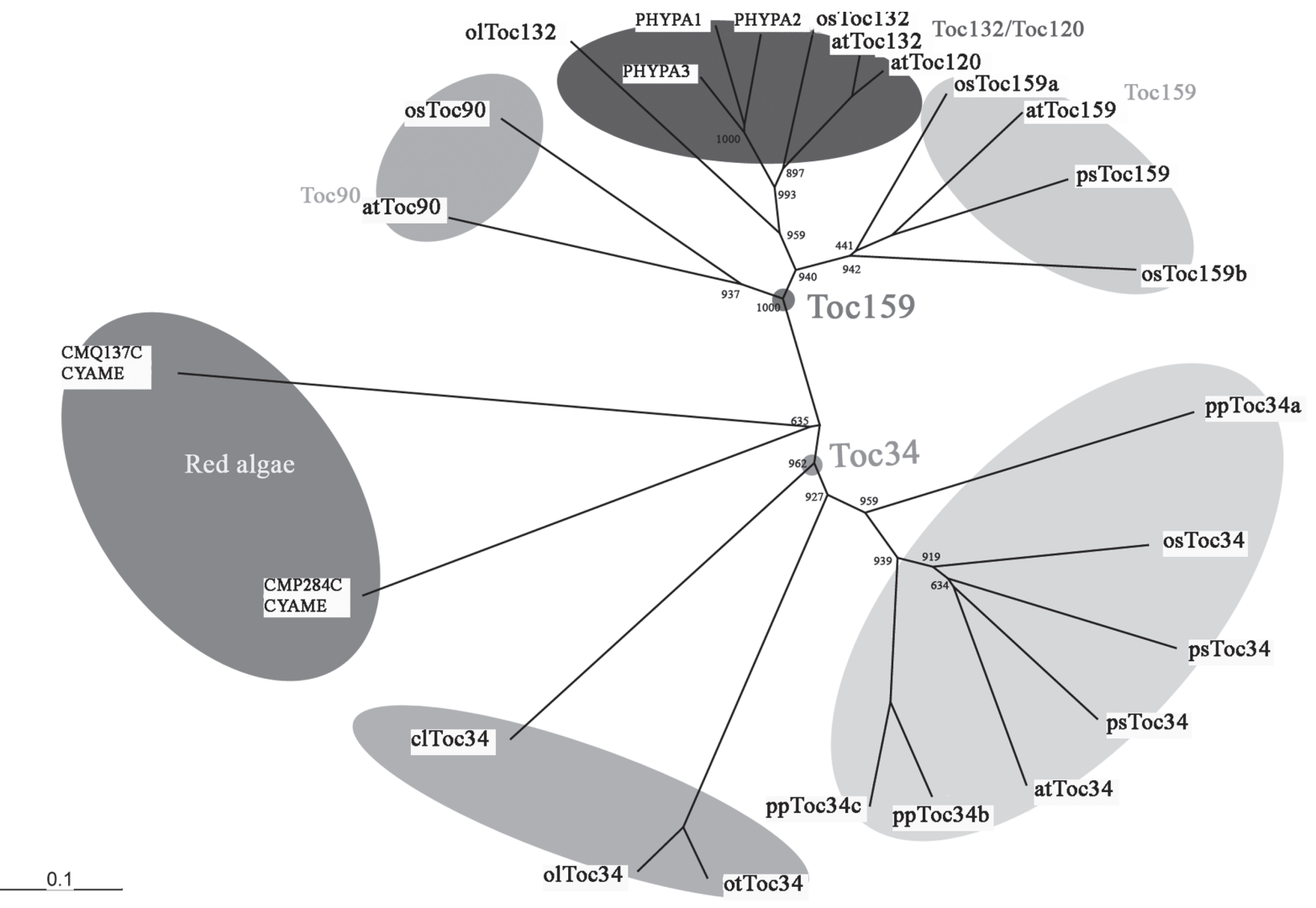

Figure 2. Unrooted phylogenetic tree of the Toc159/Toc34 families in chloroplasts. A multiple sequence alignment of members of the Toc159 and Toc64 family was performed by ClustalX v. 2.0.9. The phylogenetic relation between the Toc159 and Toc34 families was inferred by the neighbor-joining method implemented in ClustalX. The positions with gaps were excluded and 1000 bootstrap replicates were generated (values shown in the tree). The codes in the tree are as follows: clToc34, Chlamydomonas reinhardtii XP_001696644; olToc34, Ostreococcus lucimarinus XP_001417009; otToc34, Ostreococcus tauri CAL53037; ppToc34a, Physcomitrella patens PHYPADRAFT_113310; ppToc34b, Physcomitrella patens PHYPADRAFT_125509; ppToc34c, Physcomitrella patens PHYPADRAFT_211678; osToc34, Orysa sativa NP_001049508; atToc33, Arabidopsis thaliana NP_171730; atToc34, Arabidopsis thaliana NP_196119; psToc34, Pisum sativum Q41009; CMQ137C_CYAME, Cyanidioschyzon merolae CMQ137; CMQ284C_CYAME, Cyanidioschyzon merolae CMQ284; atToc90, Arabidopsis thaliana NP_197530; osToc90, Orysa sativa NP_001066359; olToc132, Ostreococcus lucimarinus XP_001421534; PHYPA1, Physcomitrella patens PHYPADRAFT_189669; PHYPA2, Physcomitrella patens PHYPADRAFT_216050; PHYPA3, Physcomitrella patens PHYPADRAFT_216964; osToc132, Orysa sativa NP_001065307; atToc132, Arabidopsis thaliana NP_179255; atToc120, Arabidopsis thaliana NP_188284; osToc159a, Orysa sativa NP_001054673; atToc159, Arabidopsis thaliana NP_567242; psToc159, Pisum sativum AAF75761; osToc159b, Orysa sativa NP_001051815. The organism name and the accession code for each sequence in the tree are indicated.

the Toc34 and Toc159 GTPases has been studied in detail, although the true sequence of events at the first contact remains a matter of debate. Two different models for the mode of precursor recognition have been proposed. The first model favors Toc159 as the initial TP receptor [59-61]. This process involves GTP hydrolysis and oligomerisation of both GTPases and results in transfer of the cargo protein to the Toc75 channel [62-64]. Transport across the membrane is then furthered by the IMS Hsp70 [52, 53]. This hypothesis has been challenged by the second model that proposes Toc34 to be the initial TP receptor [6567]. Electron microscopy performed on purified TOC complex showed a toroidal structure built by four channels enclosing a central protruding domain [68]. Stoichiometric analysis revealed four Toc75 plus four associated Toc34 molecules, forming the channel structures, and a single Toc159 subunit. It was speculated that a central Toc159 molecule represents the GTP-driven import motor that moves preproteins through the channel after receiving them from Toc34. Thus, one Toc 159 molecule could alternately interact with the four Toc34 receptors by rotation and on-andoff hetero-oligomerisation [65, 68, 69]. Moreover, it has been demonstrated that Toc159 in concert with Toc75 as a minimal TOC complex is able to achieve precursor translocation into liposomes upon GTP hydrolysis. Findings from a different study led to the conclusion that the G-domain of Toc159 is not necessary for import in vitro or in vivo [70, 71]. Moreover, it has been shown that precursors can completely bypass the receptor stage and bind to 
Toc75 directly [70]. Consequently, import can be achieved without the G-domain of Toc159. Recent findings show that when GTP hydrolysis on atToc159 is diminished, binding of precursors as well as import are increased, favoring a regulatory role of atToc 159 in preprotein recognition [72]. Although the two models do agree about GTP-mediated regulation of the Toc34/Toc159 receptors and the central channel function of Toc75, it remains to be seen how their conflicting views can be matched to satisfactorily explain preprotein recognition at TOC.

Import machinery at the inner envelope membrane of chloroplasts: the TIC complex

The composition and stoichiometry of the membrane complex involved in the import into chloroplasts at the inner envelope membrane is less known than that of the TOC machinery. Seven or eight proteins have been proposed to form the TIC complex in higher plants: Tic110 and Tic20 as putative constituents of a translocon channel; the co-chaperone Tic 40 ; and the translocon-associated Tic55, Tic32 and Tic62 subunits [73]. Tic21 is the most recently added putative component of the TIC translocon [74]. Its affiliation with TIC is, however, a matter of debate, since another group identified the protein as a metal permease [75]. Tic110 is the second most abundant protein of the inner envelope membrane and plays an essential role in plastid biogenesis, since knockout mutants of the single tic110 gene in Arabidopsis are not viable [76]. It comprises two membrane-spanning $\alpha$-helices in the extreme $\mathrm{N}$-terminus, which are necessary for targeting to and insertion into the inner envelope [77, 78]. The carboxy-terminus is largely hydrophilic. According to one hypothesis, it forms a large globular domain on the stromal side where it recruits chaperones $[79,80]$. The other hypothesis claims that regions of the $\mathrm{C}$-terminal region are within the membrane and form part of the actual translocation pore [77, 81]. New evidence from our group combines both hypotheses for the Cterminal part of Tic110; that is, it contains regions in the IMS suitable to form supercomplexes with the TOC machinery and to receive the TP of preproteins, but also a large region in the stroma, capable of interaction with molecular chaperones as well as four amphiphatic helices which build up the channel [82]. Tic40 is anchored to the inner envelope membrane by its $\mathrm{N}$-terminus [83]. The stromal C-terminal portion has a bimodular organization: a Hip/Hop domain functionally similar to the human co-chaperone Hsp70-interacting protein (Hip), and a TPR proteinprotein interaction domain $[84,85]$. Tic40 is present only in green plants, where it modulates the interaction of Tic110 and the Hsp93 chaperone, and an
Hsp100 homolog that acts as a trans translocation motor [86, 87].

Tic22 is a soluble protein in the IMS, peripherally associated to the TIC complex. It interacts with the TOC complex through Toc12 and Toc64 [52] and might participate in TIC-TOC supercomplex formation. Tic22 has been found intimately associated with Tic20, an integral membrane protein proposed to be a constituent of a translocation channel [88]. Tic20 has four predicted transmembrane helices and shares sequence similarities to bacterial amino acid transporters [7]. Four homologues are identified for Tic20 in Arabidopsis, but only two of them contain a predicted TP. The function and subcellular localization of the two Tic20 homologues with non-predicted TP are still unknown.

Tic55 is anchored to the inner envelope by two transmembrane helices at the $\mathrm{C}$-terminus and it exposes a large soluble domain in the stroma that contains a Rieske-type iron-sulfur centre and a mononuclear iron-binding site [89]. Tic62 and Tic32 are classified as short-chain dehydrogenase-reductases, but their substrate specificity in chloroplasts is still unknown. They are peripherally attached to the inner envelope at the stroma side. Tic62 has a bimodular architecture: the N-terminus is involved in $\mathrm{NADP}(\mathrm{H})$-binding; the C-terminus specifically interacts with ferredoxin-NADP-oxidoreductase (FNR) $[90,91]$. A full-length Tic62 is found only in vascular plants [92]. Tic32 also has a bimodular functional organization: an N-terminal $\mathrm{NADP}(\mathrm{H})$-binding region and a C-terminal calmodulin-binding domain [93].

The TIC complex remains more of an enigma than TOC. Although several members have been identified to date (see above), their individual functions and cooperative mechanism are still mostly elusive. One of the most important parts of a translocon is the proteinconducting channel. In the case of the TOC translocon, Toc75 has been unequivocally identified as this essential protein. In case of the TIC translocon, discussion is still ongoing about the identity of the translocation channel. Several candidates have been proposed to fulfill this essential role: Tic110, Tic20 and Tic21 [74, 81, 94]. Tic20 and Tic21 show structural similarities to the translocon at the inner membrane of mitochondria (TIM) channel proteins Tim17 and Tim23 [74, 95], yet biochemical evidence for a channel function is lacking. Undoubtedly, Tic20 has an essential role in plant development, in spite of its low abundance at the protein level, since knockout plants are not viable [94]. Tic20 could very well be a specialized pore protein, but its candidacy as the general translocation channel is not built on biochemical evidence. Support for an important role for Tic20, 
albeit not as a general import pore, comes from a recent publication by van Dooren and colleagues [96] . The authors hypothesize that Tic20 may have a regulatory role or might be involved in complex assembly. On the other hand, Tic110 features make it a good candidate for a translocation channel: it is conserved in different plastid types from multiple plant species [11]; it is expressed in cells in comparable amounts to Toc75 [97]; it shows channel activity in vitro [81]; it is found associated with precursor proteins and chaperones [77, 86]; it forms supercomplexes with the TOC complex [98]; and it is essential for plant development [76]. In any case, Tic110 has an essential role in preprotein recognition on the trans side where it associates with Tic 40 which links the central translocation channel to the import motor [99].

A detailed study of the different domains of Tic 40 demonstrated that the Hip/Hop-like domain is indeed responsible for the co-chaperone capacity, namely the binding to Hsp93 and the stimulation of its ATPase activity $[85,100]$. The TPR motifs were shown to procure the binding to Tic110. Intriguingly, it seems that upon binding of an incoming precursor at the TP, the interaction between Tic110 and Tic40 is favored, whereas the affinity of the channel to the precursor weakens. This leads to subsequent release of the precursor into the stroma, where it is processed by SPP [100]. The role of Tic40 is important for the efficiency of protein import, though not essential, because tic 40 mutants are pale but viable [84]. Very recently, it has been proposed that Tic40 is also involved in the reinsertion of proteins using the conservative sorting pathway, such as Tic110 and Tic40 itself [101]. In tic40 deletion mutants, soluble intermediates accumulate in the stroma and are reinserted into the inner envelope more slowly compared to wild-type plants. The authors speculated that Tic40 together with Tic110 and Hsp93 might constitute the reinsertion complex or, alternatively, could be an accessory component of a yet unidentified specific reinsertion complex. In contrast to Tic40, Hsp93 is indispensable for chloroplast biogenesis [102].

Apart from the channel component(s) and the motor module, there are three regulatory members of the TIC complex: Tic62, Tic55 and Tic32. As described above, all of these have features rendering them perfect candidates for sensing and signaling the redox state of chloroplasts and thereby regulating protein import at the inner envelope according to the requirements of the plastid. It has been known for some time that at least two chloroplastic precursor proteins, the non-photosynthetic ferredoxin (FdIII) and the FNR isoform II (FNRII), are differentially imported in the light and in the dark [103]. Most likely, the different redox states caused by photosynthetic activity are at least one of the reasons for this phenomenon. A good representative of the redox state is the NADPH/ $\mathrm{NADP}^{+}$ratio in the stroma. It has been demonstrated that this ratio influences TIC composition: under more oxidized conditions, Tic32 and Tic62 are closely associated with TIC, whereas reduced conditions lead to disassembly of the translocon [91, 104]. Tic62 even shuttles between a soluble stromal and a membraneattached form, depending on the redox state [91]. The soluble form of Tic62 binds even more strongly to FNR, though the significance of this interaction is unknown. The role of Tic55 is still enigmatic, though it has been recently identified in a screen for thioredoxin targets [105]. Thus, translocation could be linked to thiol-mediated regulative processes but this has to be further investigated. Another means of regulation at the inner envelope was shown to involve calcium and calmodulin (CaM) [106]. The same authors later identified Tic32 as the CaM binding target [104]. Tic32, as described above, also contains an NADPH binding site and constitutes an active dehydrogenase. Binding of the nucleotide and $\mathrm{CaM}$ seems to be mutually exclusive, so that Tic32 might represent a scaffold of fine-tuning at TIC.

\section{Outer envelope membrane protein insertion}

Proteins localized in the outer envelope membrane of chloroplasts are mostly synthesized without a cleavable N-terminal TP and they are targeted to the envelope by internal signals residing within the mature protein [107]. Several members of the outer envelope protein (OEP) family (e.g., OEP14, Toc64, Toc34) have been analyzed concerning their integration pathways [108-110]. A common denominator, at least for proteins anchored to the membrane by $\alpha$ helices, seems to reside within the hydrophobic transmembrane regions that carry the information for insertion into the lipid bilayer. The part adjacent to the transmembrane domain seems to determine the orientation of the OEP. This process was believed to be spontaneous and take place without assistance of other proteins. However, more recent results show that a proteinaceous machinery, as well as provision of energy in the form of nucleotides, facilitates the insertion into the outer envelope [109]. It has been demonstrated that OEP14 is in contact with Toc75 during insertion [111]. Similar findings have been published for the insertion of Toc34 [110], though it remains to be investigated if the same components that mediate insertion of OEP14 are involved. Recently a new player, the ankyrin repeat-containing protein AKR2, has been suggested to chaperone newly synthesized outer membrane proteins, such as OEP14, Toc64 and Toc34 proteins through the cytosol 
to the chloroplast surface [112]. It was shown that AKR2 binds to the targeting signals located in the transmembrane regions as well as in the C-terminal parts via its ankyrin modules. It is not yet known if AKR2 is likewise involved in the targeting of other outer envelope proteins consisting of $\beta$-sheets rather than $\alpha$-helices, and what kind of receptor it is using on the chloroplast surface [113]. In the case of $\beta$-barrel proteins, represented by the solute transporter family (e.g., OEP21, OEP24), it is even less clear how they are integrated into the membrane. Experimental findings so far indicate that insertion is a spontaneous process, independent of a translocation machinery and energy $[114,115]$. A notable exception in the family of B-barrel proteins is Toc75. It comprises a bipartite N-terminal TP [116]. The N-terminal portion directs the protein to the stroma via the general import pathway; the C-terminal part of the TP carries intraorganellar targeting information that seems to contain a stop-transfer signal and leads to arrest within the translocon/membrane. It remains to be investigated whether a special translocon exists that mediates the integration of $\beta$-barrel proteins into the outer envelope, comparable to the sorting and assembly machinery (SAM) in mitochondria (see below) [117]. One promising aspirant for this role would be Toc75-V, a member of the Omp85 family and distant relative of Toc75 [118].

\section{Targeting to the intermembrane space}

Information about components of the IMS is very scarce, since the compartment is hardly accessible in chloroplasts. Only two IMS proteins, Tic22 and MGD1, have so far been studied. MGD1 seems to engage TOC on its way across the outer envelope and it reaches the stroma at some point, since the TP can be cleaved by the SPP [119]. In contrast, Tic22 is not processed by the SPP and therefore probably does not cross the inner envelope at any point of translocation. It is controversial whether it uses components of TOC to travel across the outer envelope [119, 120]. The energy requirements of the two proteins also differ, suggesting that MGD1 would reach the stroma whereas Tic22 would not. Different pathways seem to exist for translocation to the IMS, at least in part, although the players involved and the mechanisms used are still elusive.

\section{Inner envelope membrane protein insertion}

Most inner envelope proteins carry $\mathrm{N}$-terminal TPs and are imported via TOC/TIC but they differ in their final targeting to the inner envelope membrane. Some use the "stop-transfer" pathway, mediated by hydrophobic signals contained in the transmembrane regions that lead to arrest of the translocating protein and lateral release into the lipid bilayer [121, 122]. Partly, these proteins carry a bipartite TP, which gives rise to a translocation intermediate that is already integral to the membrane. Other inner envelope components travel via the "conservative sorting" pathway. This is reminiscent of integration of inner membrane proteins in bacteria and involves a soluble stromal intermediate that is retargeted to the envelope by an unknown mechanism. Examples for proteins using this route are Tic110 [77, 123] and Tic40 [124]. These two again differ in their insertion characteristics, as Tic110 has one TP, and is cleaved only once by SPP, in contrast to Tic40. The latter comprises a bipartite TP and is cleaved twice, by SPP and a second protease of yet unknown identity, but which is most likely not the one responsible for the intermembrane cleavage of Toc75 [124]. Furthermore, Hsp93 has been shown to play a role in Tic110 reinsertion [123]. This feature has not yet been studied for the reinsertion process of Tic 40 .

\section{Deviations from the general TOC/TIC import pathway}

Proteomic studies revealed many proteins without a canonical TP in the chloroplasts [125]. The import properties of two of these proteins, Tic32 and cQORH, have been analyzed and the targeting information was found within the mature protein sequence [126, 127]. Although energy in the form of ATP is required for import, TOC/TIC components are not involved and their import mechanisms still await investigation. Another unexpected finding from this proteomic study was the identification of several plastid proteins carrying predicted signal peptides for the endoplasmatic reticulum (ER). Some of these may represent contaminations by ER membrane vesicles but it seems improbable that all of them are. Physical contact and biochemical interactions of ER and chloroplasts have been repeatedly reported and may have essential functions [128]. Bearing in mind that in organisms containing complex plastids, vesicle-mediated targeting is an established system, it should not come as too big a surprise that three years ago a first chloroplast protein (CAH1) was found to be delivered to its destination by travelling as ER cargo [129]. More recently, a second protein (NPP1) that uses this pathway has been identified [130]. How these proteins cross the envelope membranes and if this involves vesicle fusion and/or TOC/TIC remains to be investigated.

\section{The way to thylakoids}

The thylakoid membrane is a highly specialized membrane harboring the photosystems and the ATPase complex where the photosynthetic electron 
transfer is coupled with the chemiosomotic process. The abundant photosynthetic machinery in thylakoids is composed of subunits of both nuclear and chloroplast origin; in contrast, all the luminal proteins known so far are nuclear encoded. Proteomics and other analyses have demonstrated that systems homologous to the Sec, Tat and YidC machineries are found in thylakoids, the so-called cpSec, cpTat and Alb3 (Fig. 1) [131]. Some subunits that are transferred to thylakoids contain a bipartite TP at the N-terminus. The first part is used for translocation across the envelopes into the stroma and is cleaved off by SPP, resulting in an intermediate form of the protein. The second part guides the intermediate to thylakoids where it is processed by a thylakoidal processing peptidase (TPP), generating the mature form of the protein [132].

The Tat machinery in chloroplast thylakoids (cpTat) In chloroplasts, the twin-arginine transport system (Tat) machinery is derived from the ancient cyanobacteria where it is responsible for the export of periplasmic proteins carrying cofactors [133]. It transports mainly folded substrates and likely relies completely on the proton motif force [134, 135], not requiring any form of nucleoside triphosphates [136]. It is still not totally clear whether the proton motif force is necessary in all organisms and under all in vivo conditions [137]. Although mainly involved in the transport of luminal proteins, two membrane proteins have been described that are inserted in the thylakoidal membrane by this pathway [138,139]. The TPs recognized by cpTat are characterized by an $\mathrm{N}$ terminal charged domain (n-region), a twin arginine motif followed by a hydrophobic motif (h-region) and a polar C-terminal region (c-region) ending in the A$\mathrm{X}-\mathrm{A}$ motif, which is recognized by the TPP [140]. A special case is the Rieske $\mathrm{Fe} / \mathrm{S}$ subunit of the cytochrome $b(6)$ f complex that does not contain the typical twin arginine motif, though incidentally the Sec-machinery (see below) seems to be involved in the transport of this membrane protein [139].

The Tat system in thylakoids is conserved in plant and algal chloroplasts and consists of the Tha4, Hcf106 and cpTatC subunits that are homologous to TatA, TatB and TatC proteins respectively, found in bacteria [141]. The Hcf106 (19 kDa) and Tha4 (9 kDa) homologs are bitopic membrane proteins with an amphipathic helix positioned in the stroma; cpTatC (34 $\mathrm{kDa})$ is predicted to contain six transmembrane helices. cpTatC and Hcf106 form a stable complex in the membrane, prepared for the reception of the preprotein [142]. The binding of the precursor protein to the receptor complex recruits Tha4 that assembles with the precursor-receptor complex and forms a pore in the membrane, whose size is presumably dictated by the substrate $[143,144]$. Afterwards, Tha4 dissociates and the TP is laterally transferred to the membrane where signal cleavage occurs [140]. The signal peptide is not always removed, as in the case of the Rieske Fe/S protein where it remains and constitutes the only anchor of the protein to the membrane [139]. The mechanism of translocation is not well defined and two different models have been proposed. Whereas one model proposes that oligomers of Tha4 in the membrane polymerize around the substrate to form a pore of variable size [145], another model considers a conformational change in Tha4 which, either through an infolding of the amphipathic helices or directly through a destabilized lipid bilayer mechanism, allows the passage of the precursor protein [144]. More studies are necessary to fully understand the mechanism by which the cpTat system operates.

\section{The Sec machinery in chloroplast thylakoids (cpSec)}

The Sec system in thylakoids, derived from the general secretory pathway (Sec system) in (cyano)bacteria, and consists of a membrane-embedded protein-conducting channel and a peripherally associated motor domain [146]. In thylakoids, cpSec is composed of the minimal required components, that is, the translocation channel made up of SecY [147] and SecE [148] subunits, and the ATPase SecA [149]. It works posttranslationally for the transport of luminal proteins such as OE33 and plastocyanin, and membrane proteins such as cytochrome $\mathrm{f}$ and PsaF. It co-translationally cooperates with the SRP-dependent pathway (see below) for the biogenesis of the D1 subunit of photosystem II. The substrates are translocated in an unfolded state and the cofactors, as in the case of plastocyanin, are subsequently assembled in the lumen. The Sec-targeting signal peptides are analogous to those found in Tat-dependent signal peptides, with the exception of the twin arginine motif.

The cpSec machinery functions similarly to the bacterial Sec-pathway. SecY, a multispanning membrane protein, and $\mathrm{SecE}$, with one transmembrane helix at the C-terminus, form a $180 \mathrm{kDa}$ complex in the membrane that partially translocates the precursor. The helicase cpSecA, which contains a DEVD (AspGlu-Val-Asp) sequence in its Walker B motif, is functionally equivalent to SecA in bacteria and utilizes cycles of ATP hydrolysis to provide the driving force for translocation [150, 151]. It recognizes the signal peptide of precursor proteins in the stroma and attaches itself to the thylakoid membrane [152]. Upon ATP hydrolysis, the preprotein is partially released to the cpSecYE channel. Upon binding of SecA to SecY, ATP hydrolysis is stimulated, furthering the partial release to the cpSecYE channel. Subsequently, SecA 
deinserts from the membrane and undergoes new cycles of insertion-deinsertion involving ATP hydrolysis. This, in concert with the proton motive force energy, results in the complete translocation of the preprotein through the channel.

The SRP machinery in chloroplast thylakoids (cpSRP) The signal recognition particle (SRP) system is the major cellular machinery that mediates transport of proteins to the ER membrane or the bacterial/archaeal plasma membrane [153]. As a consequence of endosymbiotic events, a homologous system is found in thylakoids (cpSRP) [154]. cpSRP has a similar architecture to that found in bacteria, though the subunit composition and the mechanism of transport differs. The SRP in the stroma is a heterodimer that consists of cpSRP54 and cpSRP43 subunits, the latter being unique in green plant thylakoids [155]. Interestingly, it lacks the typical RNA-binding moiety found in cytosolic SRPs. Recently, the structure of cpSRP43 at atomic resolution was solved, demonstrating a comparable overall shape and charge distribution between cpSRP43 and the SRP RNA complex [156]. Moreover, a fraction of cpSRP54 free of any cpSRP43 exists in the stroma, capable of binding to 70S ribosomes [157]. As described below, this dual population of cpSRP54 in the stroma results in two different modes of translocation for cpSRP: the co-translational and the post-translational pathways. The membrane-bound receptor at the thylakoid membrane, cpFtsY, is homologous to bacterial FtsY [158]. The integral thylakoid membrane protein Albino3, or Alb3 [159], is homologous to YidC but lacks the first transmembrane helix found in bacteria, and therefore consists of 5 transmembrane helices with the $\mathrm{N}$-terminus located in the thylakoid and a Cterminal soluble region oriented towards the stroma. As in bacteria, the transport process driven by the SRP system is GTP regulated through cpSRP54 and cpFtsY subunits. These GTPases comprise a unique subgroup in the GTPase superfamily [153] and reciprocally activate one another upon complex formation [160]. The complex is only stable when the two proteins are in the GTP-bound state; upon binding, GTP is hydrolyzed and the subunits dissociate [161]. In the co-translational insertion pathway, cpSRP cooperates with the Sec machinery in the insertion of some chloroplast-encoded proteins, such as the D1 protein, into thylakoids [162]. A transient binding between cpSRP54 and the nascent protein attached to the ribosome has been demonstrated during the early phase of elongation with the binding affinity decreasing as elongation proceeds [163]. The interaction of cpSRP54 with cpFtsY stimulates GTP hydrolysis and the nascent chain is passed on to the $\mathrm{Alb} 3 / \mathrm{Sec}$ translocon [162].

Still the most well known substrate for cpSRP is the family composed of some nuclear-encoded light harvesting chlorophyll a/b binding proteins (LHCP) [155]. The insertion mechanism proceeds post-translationally and is believed to be Sec-independent. The thylakoid translocation starts with the recognition of the signal peptide of LHCP in the stroma by the heterodimer composed of cpSRP54 and cpSRP43. Recently, the interaction of these two subunits was thermodynamically and structurally characterized [164]. The formation of the transit complex is initiated by the binding of LHCP to an ankyrin region in cpSRP43 [156]. Afterwards, the cpSRP54 contacts and binds LHCP. The transit complex formed by the substrate together with cpSRP54-GTP/cpSRP43 proteins is recognized by the receptor cpFtsY. Two mechanisms have been proposed: one is that FtsY, found in two pools, soluble and membrane associated like in bacteria, recognizes the complex in the stroma and shepherds it to thylakoids [165]; another relies on the fact that FtsY is not soluble at all in the stroma, but extrinsically attached to the thylakoid membrane [166]. The complex of cpSRP54/cpFtsY induces GTP hydrolysis and subsequently the heterodimer cpSRP54/cpSRP43 is released from cpFtsY [161]. The substrate is then targeted to Alb3 and laterally incorporated into the membrane. New proposals establish that cpSRP43 has capabilities in itself to drive LHC protein to Alb3 in the absence of cpSRP54 and cpFtsY [167].

\section{Spontaneous insertion}

A spontaneous insertion of a membrane protein in thylakoids, i.e. without the participation of any stromal factor, membrane protein translocator or nucleoside triphosphates (NTPs), was first described for CFo-II [168]. Since then, some other proteins have been recognized that follow this method of insertion (e.g., SecE, PsaK, PsbS). The TP of this group of proteins is highly similar to that found in proteins following the other translocation pathways in thylakoids. However, some differences are noticeable, such as the occurrence of acidic residues in the c-region [169]. The presence of two hydrophobic helices surrounding the $\mathrm{N}$-terminus of the mature protein seems crucial for this way of membrane insertion; one helix formed by the TP and another immediately after the hydrophilic N-terminal region. The insertion mechanism seems to proceed with the burial of the $\mathrm{N}$-terminal hydrophilic region by the two hydrophobic helices during translocation across the membrane, forming a transmembrane loop intermediate [170]. Once the protein is inserted, the signal peptide might 

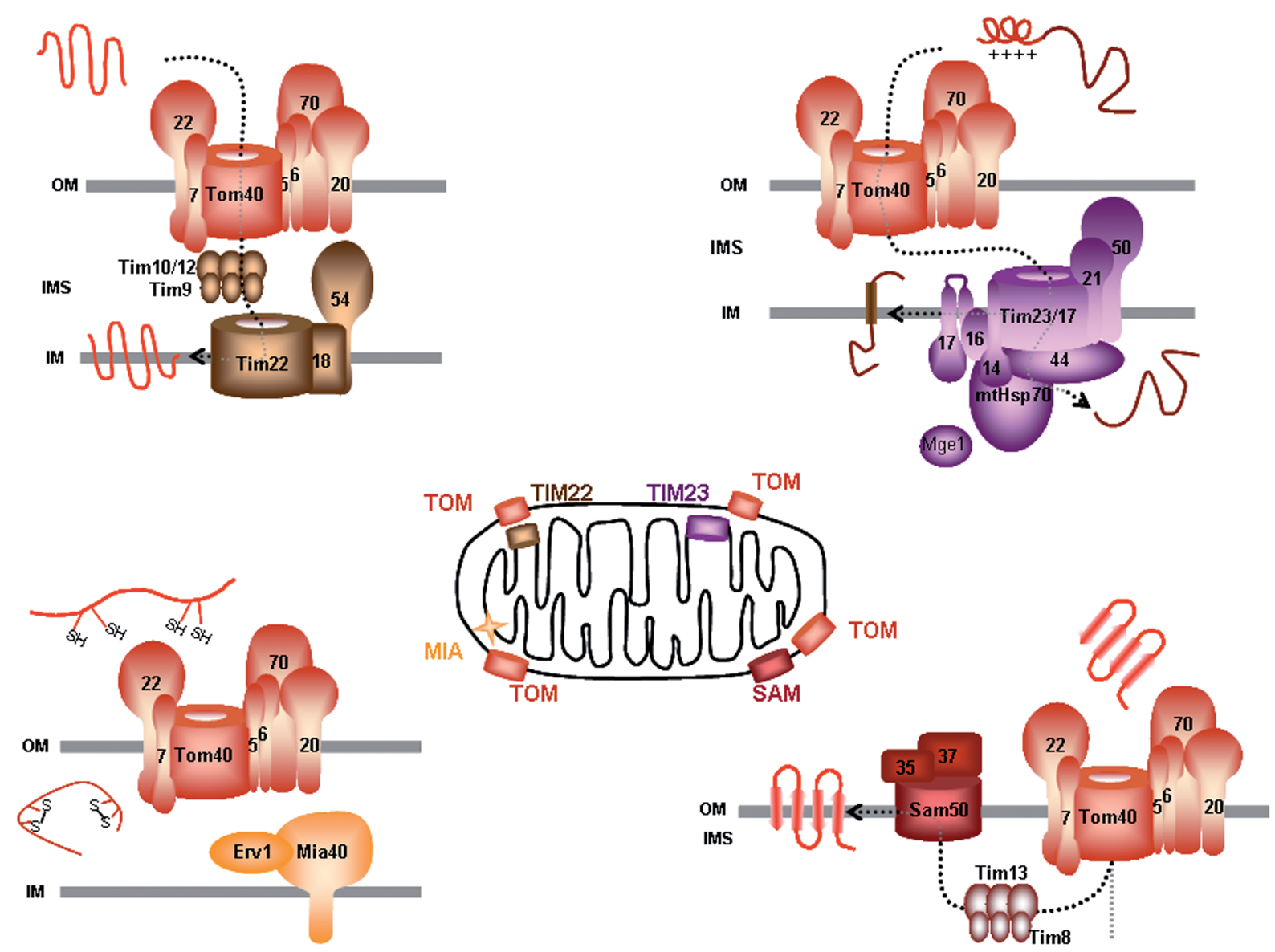

Figure 3. Overview of mitochondrial translocases. Different types of precursors and their targeting characteristics are indicated together with the model of TOM. Complexes and components are color coded for convenient allocation. For details please refer to the text.

be cleaved or not, in the latter case forming part of the membrane-spanning region of the protein.

\section{Protein import in mitochondria}

Most results concerning protein import into mitochondria have been obtained by working with yeast as a model organism. Plant mitochondria have slightly different components and, to some extent, a different mechanism.

Import of preproteins to mitochondria involves several membrane complexes: the translocases at the outer and inner membrane of mitochondria (TOM and TIM complexes, respectively); the sorting and assembly machinery (SAM) for the insertion of $\beta$ barrel proteins into the outer membrane, and the presequence translocase associated motor (PAM), for translocation into the matrix (Fig. 3) [171].

\section{Targeting sequences}

Most mitochondrial proteins comprise targeting sequences that share certain features with their chlor- oplast counterparts, e.g. they are positively charged. The N-terminal targeting sequences are also called matrix-targeting sequences (MTSs), since they direct the protein into the mitochondrial matrix. They do not contain conserved primary sequences but they comprise a characteristic secondary structure: they form amphipathic helices, resulting in one positive and one hydrophobic surface [172]. This is crucial for their interaction with receptor proteins of the TOM machinery. A large number of mitochondrial proteins have, however, internal targeting signals whose characteristics are less well defined [171]. All outer membrane proteins belong to this class, but also several others which are sorted to the matrix or the inner membrane. Hydrophobic inner membrane proteins from the mitochondrial carrier family contain internal targeting information within their transmembrane domains [171]. All mitochondrial targeting signals are recognized by receptors of the TOM machinery and then guided further to their specific translocons. This will be discussed later. 
Translocation through the TOM complex

En route into mitochondria, all proteins first encounter the TOM complex. The core module of this complex, $400 \mathrm{kDa}$ in size, is made up of the integral membrane proteins Tom 40 that form the protein channel, and the single $\alpha$-helical transmembrane subunits Tom22, Tom5, Tom6 and Tom7. More loosely associated are the primary receptors Tom70 and Tom 20 that are anchored in the outer membrane of mitochondria by a single transmembrane helix. As in the case of chloroplast subunits, the numbers indicate their molecular mass.

Tom 40 is the major component of the TOM complex and constitutes the hydrophilic pore-forming subunit of the mitochondrial general import pore [173]. It is predicted to have an amphipathic $\beta$-barrel structure deeply embedded in the membrane, as does Toc75, the pore-forming protein in the outer envelope membrane of chloroplasts (see above). Topologically, Tom70 and Tom 22 have a small N-terminal region in the IMS and a bigger $\mathrm{C}$-terminal soluble domain exposed into the cytosol. This forms the receptor domain where TPR protein-protein interaction motifs, reminiscent of Toc64, are recognized [174]. However, the number and features of the TPR motifs differ, and this results in different, though partially overlapping substrate specificities: Tom70, with 11 TRP repetitions organized into a right-handed superhelix [175], preferably interacts with hydrophobic proteins destined for the mitochondrial inner membrane, as well as the cytosolic chaperones of the Hsp70 family. Tom20, where just one TPR is recognized, preferentially binds precursor proteins comprising MTSs [176-178]. Tom22, tightly associated with Tom40, cooperates in the transfer of preproteins from Tom70/Tom 22 to Tom40. Additionally, it can act as a receptor for a small number of proteins [179]. Tom22 is described as a structural organizer of the TOM complex [180] that exposes the C-terminal region to the IMS and the $\mathrm{N}$-terminal domain into the cytosol to dock the other receptors of the TOM complex. Its only transmembrane helix forms part of the core complex with Tom 40 and is essential for the integrity of the complex. The region exposed to the IMS holds the presequence in the IMS after translocation [181] and also serves as a contact site with the TIM23 complex [182]. The Tom22 subunit is known as Tom9 in plants (see below). The other constituents, Tom5, Tom6 and Tom7, are located close to the translocation pore and regulate the interactions within the complex. Tom 5 accepts substrates from the receptors and mediates their insertion into Tom 40 [183]; Tom6 and Tom 7 modulate the dynamics of the TOM complex [184].
All substrates are recognized by either of the two primary receptors, Tom 70 or Tom 20 . The TPR motifs of Tom 70 and Tom 20 are part of a hydrophobic groove that interacts with the hydrophobic signals or the hydrophobic surface of the amphiphilic MTSs [177, 178]. Upon binding, both receptors transfer their accepted cargo to the translocation pore, Tom40, via Tom22. Tom40, associated with the small helper compounds, Tom7, Tom6 and Tom5, mediates translocation of virtually all mitochondrial proteins including Tom 40 itself. During translocation, Tom40 undergoes dynamic conformational changes essential for its function as a channel [185]. According to the binding chain hypothesis, the driving force for translocation through the TOM complex does not depend on ATP or the membrane potential across the inner membrane: the translocating substrates interact with several binding sites of increasing affinity that form a guidance system for preproteins across the outer membrane [186].

\section{Outer membrane proteins and SAM}

It was quite recently discovered that $\beta$-barrel proteins located in the outer membrane use a specialized pathway for their integration into the membrane. After transport through Tom40, 3 -barrel proteins are recognized by two small Tim proteins (Tim8 and Tim13) in the IMS (see below), which guide them to the SAM complex (also called TOB). This consists of the integral membrane protein Sam50 (also known as Tob55) and the peripheral subunits Sam35 (also known as Tob38) and Sam37 (also known as Tom37 or Mas37) [187-190]. Sam50 is a member of the Omp85 family that has been shown to be crucially involved in insertion of $\beta$-barrel proteins into the bacterial outer membrane [187]. Thus, Sam50 most likely represents the "integrase" for $\beta$-barrel proteins. The function of the other two SAM components is not completely clear yet. Sam35 might cooperate with Sam50, whereas Sam37 might be involved in the release of $\beta$-barrel intermediates to the membrane [117]. Protein integration into the outer membrane is independent on energy, indicating that the process itself is energetically favorable. The mechanistic action of SAM remains unknown to date. New roles in the biogenesis of $\alpha$-helical proteins have been very recently ascribed to the SAM complex [191].

\section{Proteins destined for the IMS}

All proteins that reside in the IMS are nuclear encoded, but only a few of them carry MTSs. Two different pathways participate in the import of IMS proteins [192]. Mitochondrial IMS proteins with MTSs have a bipartite presequence, characterized by a hydrophobic sorting signal downstream of the 
matrix targeting sequence. First the $\mathrm{N}$-terminal region of the presequence directs the preprotein to the TIM23 complex (see below); then the hydrophobic sorting signal anchors in the inner membrane where, after a second processing step at the IMS and proteolytical removal of the presequence behind the sorting signal, the soluble mature protein is released to the IMS. Most of the IMS proteins, however, do not contain MTSs and they associate with specific factors in the IMS after TOM translocation. These specific factors act as folding catalysts, incorporating cofactors and/or promoting oxidative events, folding some substrates that "trap" them in the IMS. The IMS contains a complete machinery to catalyze the oxidative folding of proteins and reflects the evolutionary origin of this compartment from the periplasmic space of the prokaryotic ancestor of mitochondria [193]. The substrates of this specific intermembrane space pathway, called mitochondrial IMS import and assembly pathway (MIA), are proteins that carry conserved cysteine motifs. After passage through TOM, the substrates are intercepted by Mia40, a bitopic inner membrane protein with a large domain into the IMS, that interacts with the incoming precursors by forming intermolecular disulfide bridges [194]. Upon release from Mia40, the substrate proteins are oxidized and functionally folded. For reoxidation, Mia40 interacts with the sulfhydryl oxidase Erv1 [193], which itself is regenerated by transferring electrons to cytochrome $\mathrm{c}$ in the respiratory chain. This releases its electrons to molecular oxygen, thereby completing the electron transfer chain of the intermembrane space assembly pathway. Thus, the processes taking part in the MIA pathway seem to take the necessary energy from the formation and release of disulphide bonds.

Those substrates destined for the inner membrane or matrix are intercepted in the IMS by the small Tim proteins (Tim 8, Tim9, Tim10, Tim12 and Tim13) [195]. These small proteins fulfill crucial functions in the sorting of the incoming proteins. They form heterohexameric complexes [196, 197], Tim9/Tim10, Tim9/Tim10/Tim12 and Tim8/Tim13, that interact with precursor proteins and shelter them on their further way either to the SAM complex in the outer membrane or to the TIM complexes.

\section{Matrix and inner membrane targeting}

A distinction is made between two different protein import pathways in the inner membrane: the general import pathway for proteins that contain MTSs; targeted to the TIM23 complex; and the carrier import pathway for internal targeting sequences found in most inner membrane proteins, laterally inserted into the inner membrane by the TIM 22 complex. On reaching the matrix space, the precursors are cleaved by the mitochondrial processing peptidase (MPP) and undergo chaperone-assisted folding and assembly to functional complexes.

\section{TIM23}

The TIM23 complex is responsible for translocation of matrix-targeted proteins as well as a limited number of inner membrane proteins and IMS proteins. Both classes of TIM23 substrates carry typical MTSs. Inner membrane proteins with a single transmembrane helix are imported by a stop-transfer mechanism, where the single transmembrane helix acts as stop-transfer signal. Inner membrane proteins with more than one transmembrane helix are first fully transported into the matrix, from where they are relocated to the inner membrane with the assistance of the essential Oxa1p, a YidC/Alb3 homolog [198]. This conservative sorting pathway has most probably been inherited from the bacterial ancestor and is reminiscent of the import mechanism of Tic110 in chloroplasts (see above). The Oxa1p complex is also involved in translocation of several mitochondria-encoded inner membrane proteins $[154,198]$. The TIM23 translocase consists of several subunits that are dynamically associated depending on the substrate protein that is being translocated. The TIM23 constituents fall into two different classes: members forming the protein-conducting channel and those constituting the import motor (PAM). The first group is formed by Tim23, Tim17, Tim50 and Tim21, whereas Tim44, Tim16 (also known as Pam16), Tim14 (or Pam18), the mitochondrial Hsp70 chaperone (mtHsp70) and Mge1 belong to the latter group. Tim 23 and Tim17 together form the actual pore $[199,200]$. Both proteins have a similar size and a membrane topology that consists of four hydrophobic transmembrane helices, with the $\mathrm{N}$ - and C-termini in the IMS. Tim23 is different in that the longer N-terminus of Tim23 spans the IMS and protrudes into the cytosol, thus facilitating the transfer of precursor proteins [201].

In general, precursor proteins are handed over from TOM to TIM23, engaging the IMS parts of Tim50 and $\operatorname{Tim} 23$ [202]. At this step, the $\mathrm{pH}$ gradient across the inner membrane is required as the energy source. Once emerging from the TIM channel, matrix-destined precursors are caught by members of the PAM complex. First, Tim44, a largely hydrophilic matrix protein attached to the inner membrane [203], binds to the emerging precursor and passes it on to mtHsp70. With the help of Tim14 and Tim16 as cochaperones [204, 205], their job most likely being the regulation of ATP hydrolysis, mtHsp70 binds tightly to the incoming precursor and detaches from Tim44. Translocation into the matrix is now furthered and 
takes place in a stepwise manner, due to binding of more mtHsp70 molecules as the precursor moves along through the channel [206]. Mge1 acts as a nucleotide exchange factor, whose performance leads to decreased affinity of mtHsp70 to the precursor and eventually to its release into the matrix. The mechanism of how the motor works has been a matter of debate, but today results favor the described Brownian-ratchet mechanism over the power-stroke mechanism [207]. The form of TIM23 associated with the import motor PAM is called TIM23 $3^{\mathrm{MOTOR}}$ [208].

Another type of TIM23 mediates insertion of singlespan inner membrane proteins. This form of TIM23 comprises Tim 21 and was termed TIM $23^{\text {SORT }}$ [208]. Tim21 was shown to interact with the IMS part of Tom 22, thereby possibly mediating interaction of TOM and TIM23. Another proposed function of Tim21 was the regulation of import motor association. However, some groups suggested that Tim21 is replaced at some point by Tim14-Tim16, suggesting that the presence of Tim21 alone does not exclusively destine TIM23 as the sorting form of the translocase [182]. Consequently, the fine-tuning of complex composition as well as the details of the translocating mechanisms need to be clarified. A second class of precursor proteins engaging TIM $23^{\text {SORT }}$ is represented by some IMS components that contain MTSs, as mentioned above. Still, the TOM $23^{\text {SORT }}$ model has recently been challenged by evidence that Tim 23 activity can be remodeled by association with different Tim polypeptides [209].

\section{TIM22}

The so-called carrier proteins are synthesized without a cleavable targeting sequence and characteristically have an even number of hydrophobic transmembrane helices, with their $\mathrm{N}$ - and $\mathrm{C}$-termini oriented towards the IMS. Their internal sorting information leads them on to the TIM22-mediated pathway, which is accordingly termed the "carrier import pathway". It not only involves the membrane-inserted compounds of TIM22 (Tim22, Tim18 and Tim54) but also includes the small Tim proteins Tim9, Tim10 and Tim12 in the IMS [210]. The voltage-dependent channel Tim22 is predicted to be made up of four transmembrane helices [211]. It resembles Tim 23 and Tim17, with respect to structure and topology. The molecular functions of Tim18 and Tim54 in TIM22 are still unknown. New experiments suggest a role of Tim18 in TIM22 complex assembly, whereas Tim54, which exposes a large soluble domain into the IMS, might form the docking site for the small Tim proteins [212]. Import via TIM22 is subdivided into several steps: it starts with precursor recognition by Tom70 at the mitochondrial surface that essentially depends on the presence of Hsp90/Hsp70 on the precursor [213]. Upon emerging from Tom40, carrier proteins are bound by the TIM10 complex formed by the hexameric Tim9/Tim10 assembly, which shield hydrophobic domains from unproductive interactions and guide precursor proteins to the TIM22 translocase. The insertion by TIM22 is strictly dependent on the membrane potential. Within the membrane, carrier proteins are then assembled to functional dimers [171].

\section{Mitochondrial protein import in plant cells}

Most of the knowledge about the mitochondrial import apparatus had been acquired in yeast or mammals. When people began looking closely at plant mitochondria they found that plant TOM, in particular, is slightly different from its non-plant counterparts [214]. Like in chloroplasts, many members of the TOM and TIM families are encoded by multiple gene families [215-217]. Only three TOM members are conserved throughout all species: the translocation pore Tom 40 , the organizer Tom 22 and the small Tom7 protein. Two Tom40 isoforms, highly similar to those of fungi and mammals, are found in Arabidopsis. Tom 22 is present in green plants (Arabidopsis, Physcomitrella and Ostreococcus) as a short version named Tom9. It lacks the large N-terminal acidic cis-receptor region in the cytosol that characterizes Tom22. This might have been an adaptive change associated with an increased requirement for selectivity in protein targeting [215]. In Arabidopsis, two Tom9 isoforms are present that differ in the trans domain; their significance is still unknown. Also, two Tom7 isoforms are recognized in Arabidopsis [215]. On the other hand, the receptor components Tom70 and Tom 20 seem to be missing, at least if one looks on the sequence level. Intriguingly, a protein structurally and functionally similar to Tom 20 was identified in plants [218]. However, though the individual structural domains of plant Tom20 are similar to e.g. rat Tom20, they occur in reversed order. Whereas atTom 20 is anchored to the outer membrane via its C-terminus, rat Tom 20 comprises an N-terminal membrane anchor. Sequence and structural analyses concluded that these proteins do not share a common ancestor but are the result of convergent evolution [218]. This points to the essential importance of this import receptor, since animal/plant mitochondria needed to "acquire" a protein with such a function to increase targeting specificity and efficiency of translocation. Four Tom 20 isoforms are recognized in the Arabidopsis genome, though three isoforms (Tom20-2, Tom20-3 and Tom20-4) have been detected only by proteomics [216]. In the case of Tom70, its function might have been taken over by 
OM64, a Toc64 homolog (see above) [51]. Additionally, Tom5 and Tom6 subunits have been experimentally identified in Arabidopsis [219].

In contrast to TOM, plant TIM complexes consist of homologous proteins highly similar to their yeast/ mammal counterparts [220]. However, some TIM members differ in the distribution of certain motifs. Subunits Tim17, Tim23, Tim44 and Tim50 have been experimentally confirmed by proteomics [216]. Three different isoforms are encoded in the Arabidopsis genome for Tim17 and Tim23. In a manner analogous to yeast Tim23, plant Tim17 (isoforms atTim17-1 and atTim17-2, but not atTim17-3) comprises a long Cterminal extension that links the outer and inner membrane and is involved in TP binding [220]. In plants, however, Tim23 lacks this extension, which might explain the absence of Tim21[217]. Proteomic analyses suggest a functional specialization in expression since Tim17-1, for example, is not present in nongreen organs and its expression increases during development. Similarly, Tim23-3 and Tim44-1 are highly expressed in roots $[216,220]$. The presence of Tim14 and Tim 16 is concluded by sequence comparison [217]. Interestingly, many components of the carrier import pathway have not been identified at a sequence level in plants. This is the case for Tim18, Tim54 and the small subunit Tim12 [217, 220]. Besides, Tim 22 and the small Tim proteins (Tim8/Tim13 and Tim9/Tim10) have been identified by proteomics [216]. It is presently unknown whether other proteins substitute Tim 18 and Tim54 function in plants. Finally, just a few words to mention that other important sorting machineries such as SAM, MIA and Oxa1p are also present in plants $[217,221]$.

\section{Dual targeting}

Since researchers concentrated on looking for features rendering organelle-targeting specific, it came as a huge surprise that several proteins exist which are destined for both chloroplasts and mitochondria. Up until now approximately 50 dual-targeted proteins have been identified. Dual-targeting signals seem to be quite similar to chloroplast and mitochondrial ones. Some residues, e.g. arginine, seem to be more significant for mitochondrial recognition [222], whereas hydroxylated residues carry more weight in plastid import [223]. Interaction with cytosolic components might play a regulatory role in the distribution to the respective organelles. Another intriguing possibility is the "pre-sorting" by differential targeting of mRNA [224], but this remains elusive. In contrast to single-targeted proteins where the mature parts may influence import efficiency but not the targeting itself, in the case of dual-targeting, the mature protein has a more decisive role [225]. Concerning the functions of proteins localized in both organelles, they seem to be particularly involved in basic processes such as the cell cycle and DNA and protein synthesis [223]. Thus, having proteins delivered to both chloroplasts and mitochondria may ensure their capability of performing essential functions co-coordinately and thereby may represent a manner of interorganellar communication.

Acknowledgments. This work was supported by Deutsche Forschungsgemeinschaft Grant SFB594 and Fundación Ramón Areces $(\mathrm{MB})$.

1 Gray, M.W. (1992). The endosymbiont hypothesis revisited Int. Rev. Cytol. 141, 233-357.

2 Lang, B.F., Gray, M.W. and Burger, G. (1999). Mitochondrial genome evolution and the origin of eukaryotes. Annu. Rev. Genet. 33, 351-397.

3 Reyes-Prieto, A., Weber, A.P.M. and Bhattacharya, D. (2007). The origin and establishment of the plastid in algae and plants. Annu. Rev. Genet. 41, 147-168.

4 Gould, S.B., Waller, R.R. and McFadden, G.I. (2008). Plastid evolution. Annu. Rev. Plant Biol. 59, 491-517.

5 Martin, W., Stoebe, B., Goremykin, V., Hansmann, S., Hasegawa, M. and Kowallik, K.V. (1998). Gene transfer to the nucleus and the evolution of chloroplasts. Nature 393, $162-165$

6 Dolezal, P., Likic, V., Tachezy, J. and Lithgow, T. (2006). Evolution of the molecular machines for protein import into mitochondria. Science 313, 314-318.

7 Reumann, S., Inoue, K. and Keegstra, K. (2005). Evolution of the general protein import pathway of plastids (Review). Mol. Membr. Biol. 22, 73-U20.

8 Wickner, W. and Schekman, R. (2005). Protein translocation across biological membranes. Science 310, 1452-1456.

9 Mackenzie, S. and McIntosh, L. (1999). Higher plant mitochondria. Plant Cell 11, 571-585.

10 Strzalka, K., Ngernprasirtsiri, J., Watanabe, A. and Akazawa, T. (1987). Sycamore amyloplasts can import and process precursors of nuclear encoded chloroplast proteins. Biochem. Biophys. Res. Commun. 149, 799-806.

11 Davila-Aponte, J.A., Inoue, K. and Keegstra, K. (2003). Two chloroplastic protein translocation components, Tic110 and Toc75, are conserved in different plastid types from multiple plant species. Plant Mol. Biol. 51, 175-181.

12 Wan, J.X., Blakeley, S.D., Dennis, D.T. and Ko, K. (1996). Transit peptides play a major role in the preferential import of proteins into leucoplasts and chloroplasts. J. Biol. Chem. 271, 31227-31233.

13 Bruce, B.D. (2000). Chloroplast transit peptides: structure, function and evolution. Trends Cell Biol. 10, 440-447.

14 Bruce, B.D. (2001). The paradox of plastid transit peptides: conservation of function despite divergence in primary structure. Biochim. Biophys. Acta-Mol. Cell Res. 1541, 2-21.

15 Krimm, I., Gans, P., Hernandez, J.F., Arlaud, G.J. and Lancelin, J.M. (1999). A coil-helix instead of a helix-coil motif can be induced in a chloroplast transit peptide from Chlamydomonas reinhardtii. Eur. J. Biochem. 265, 171-180.

16 Vonheijne, G. and Nishikawa, K. (1991). Chloroplast transit peptides - the perfect random coil. FEBS Lett. 278, 1-3.

17 May, T. and Soll, J. (2000). 14-3-3 proteins form a guidance complex with chloroplast precursor proteins in plants. Plant Cell 12, 53-63.

18 Zhang, X.P. and Glaser, E. (2002). Interaction of plant mitochondrial and chloroplast signal peptides with the 
Hsp70 molecular chaperone. Trends in Plant Science 7, 1421.

19 Wienk, H.L.J., Wechselberger, R.W., Czisch, M. and de Kruijff, B. (2000). Structure, dynamics, and insertion of a chloroplast targeting peptide in mixed micelles. Biochemistry (Mosc.) 39, 8219-8227.

20 Wienk, H.L.J., Wechselberger, R., Czisch, M. and de Kruijff, B. (2000). Structural information for a chloroplast transit peptide in a lipid-mimicking environment. Biophys. J. 78, 413A-413A.

21 Chen, L.J. and Li, H.M. (1998). A mutant deficient in the plastid lipid DGD is defective in protein import into chloroplasts. Plant J. 16, 33-39.

22 Lee, D.W., Kim, J.K., Lee, S., Choi, S., Kim, S. and Hwang, I. (2008). Arabidopsis nuclear-encoded plastid transit peptides contain multiple sequence subgroups with distinctive chloroplast-targeting sequence motifs. Plant Cell 20, 1603-1622.

23 Rial, D.V., Arakaki, A.K. and Ceccarelli, E.A. (2000). Interaction of the targeting sequence of chloroplast precursors with Hsp70 molecular chaperones. Eur. J. Biochem. 267, 6239-6248.

24 Rial, D.V., Ottado, J. and Ceccarelli, E.A. (2003). Precursors with altered affinity for Hsp70 in their transit peptides are efficiently imported into chloroplasts. J. Biol. Chem. 278, 46473-46481.

25 Rial, D.V., Arakaki, A.K., Almara, A.M., Orellano, E.G. and Ceccarelli, E.A. (2006). Chloroplast Hsp70 s are not involved in the import of ferredoxin-NADP $(+)$ reductase precursor. Physiol. Plant. 128, 618-632.

26 Waegemann, K. and Soll, J. (1996). Phosphorylation of the transit sequence of chloroplast precursor proteins. J. Biol. Chem. 271, 6545-6554.

27 Martin, T., Sharma, R., Sippel, C., Waegemann, K., Soll, J. and Vothknecht, U.C. (2006). A protein kinase family in Arabidopsis phosphorylates chloroplast precursor proteins. J. Biol. Chem. 281, 40216-40223.

28 Qbadou, S., Becker, T., Mirus, O., Tews, I., Soll, J. and Schleiff, E. (2006). The molecular chaperone Hsp90 delivers precursor proteins to the chloroplast import receptor Toc64. EMBO J. $25,1836-1847$.

29 Hofmann, N.R. and Theg, S.M. (2005). Toc64 is not required for import of proteins into chloroplasts in the moss Physcomitrella patens. Plant J. 43, 675-687.

30 Aronsson, H., Boij, P., Patel, R., Wardle, A., Topel, M. and Jarvis, P. (2007). Toc64/OEP64 is not essential for the efficient import of proteins into chloroplasts in Arabidopsis thaliana. Plant J. 52, 53-68.

31 Oreb, M., Tews, I. and Schleiff, E. (2008). Policing Tic 'n' Toc, the doorway to chloroplasts. Trends Cell Biol. 18, 19-27.

32 Bolter, B., Soll, J., Schulz, A., Hinnah, S. and Wagner, R. (1998). Origin of a chloroplast protein importer. Proc. Natl. Acad. Sci. U. S. A. 95, 15831-15836.

33 Gentle, I.E., Burri, L. and Lithgow, T. (2005). Molecular architecture and function of the Omp85 family of proteins. Mol. Microbiol. 58, 1216-1225.

34 Clantin, B., Delattre, A.S., Rucktooa, P., Saint, N., Meli, A.C., Locht, C., Jacob-Dubuisson, F. and Villeret, V. (2007). Structure of the membrane protein FhaC: A member of the Omp85-TpsB transporter superfamily. Science 317, 957-961.

35 Hinnah, S.C., Wagner, R., Sveshnikova, N., Harrer, R. and Soll, J. (2002). The chloroplast protein import channel Toc75: Pore properties and interaction with transit peptides. Biophys. J. 83, 899-911.

36 Ertel, F., Mirus, O., Bredemeier, R., Moslavac, S., Becker, T. and Schleiff, E. (2005). The evolutionarily related beta-barrel polypeptide transporters from Pisum sativum and Nostoc PCC7120 contain two distinct functional domains. J. Biol. Chem. 280, 28281-28289.

37 Baldwin, A., Wardle, A., Patel, R., Dudley, P., Park, S.K., Twell, D., Inoue, K. and Jarvis, P. (2005). A molecular-genetic study of the Arabidopsis Toc75 gene family. Plant Physiol. $138,715-733$.
38 Patel, R., Hsu, S.C., Bédard, J., Inoue, K. and Jarvis, P. (2008). The Omp85-related chloroplast outer envelope protein OEP80 is essential for viability in Arabidopsis. Plant Physiol. $148,235-245$.

39 Kalanon, M. and McFadden, G.I. (2008). The chloroplast protein translocation complexes of Chlamydomonas reinhardtii: A bioinformatic comparison of Toc and Tic components in plants, green algae and red algae. Genetics 179, $95-$ 112.

40 May, T. and Soll, J. (1998). Positive charges determine the topology and functionality of the transmembrane domain in the chloroplastic outer envelope protein Toc34. J. Cell Biol. $141,895-904$.

41 Sun, Y.J., Forouhar, F., Li, H.M., Tu, S.L., Yeh, Y.H., Kao, S., Shr, H.L., Chou, C.C., Chen, C.P. and Hsiao, C.D. (2002). Crystal structure of pea Toc34, a novel GTPase of the chloroplast protein translocon. Nat. Struct. Biol. 9, 95-100.

42 Koenig, P., Oreb, M., Hofle, A., Kaltofen, S., Rippe, K. Sinning, I., Schleiff, E. and Tews, I. (2008). The GTPase cycle of the chloroplast import receptors Toc33/Toc34: Implications from monomeric and dimeric structures. Structure 16, 585596.

43 Jelic, M., Soll, J. and Schleiff, E. (2003). Two Toc34 homologues with different properties. Biochemistry (Mosc.) 42, 5906-5916.

44 Aronsson, H., Combe, J., Patel, R. and Jarvis, P. (2006). In vivo assessment of the significance of phosphorylation of the Arabidopsis chloroplast protein import receptor, atToc33. FEBS Lett. 580, 649-655.

45 Jarvis, P., Chen, L.J., Li, H.M., Pete, C.A., Fankhauser, C. and Chory, J. (1998). An Arabidopsis mutant defective in the plastid general protein import apparatus. Science 282, 100 103.

46 Weirich, C.S., Erzberger, J.P. and Barral, Y. (2008). The septin family of GTPases: Architecture and dynamics. Nat. Rev. Mol. Cell Biol. 9, 478-489.

47 Hiltbrunner, A., Bauer, J., Alvarez-Huerta, M. and Kessler, F. (2001). Protein translocon at the Arabidopsis outer chloroplast membrane. Biochem. Cell Biol. 79, 629-635.

48 Ivanova, Y., Smith, M.D., Chen, K.H. and Schnell, D.J. (2004) Members of the Toc159 import receptor family represent distinct pathways for protein targeting to plastids. Mol. Biol. Cell 15, 3379-3392.

49 Sohrt, K. and Soll, J. (2000). Toc64, a new component of the protein translocon of chloroplasts. J. Cell Biol. 148, $1213-$ 1221.

50 Qbadou, S., Becker, T., Bionda, T., Reger, K., Ruprecht, M., Soll, J. and Schleiff, E. (2007). Toc64 - A preprotein-receptor at the outer membrane with bipartide function. J. Mol. Biol. $367,1330-1346$.

51 Chew, O., Lister, R., Qbadou, S., Heazlewood, J.L., Soll, J., Schleiff, E., Millar, A.H. and Whelan, J. (2004). A plant outer mitochondrial membrane protein with high amino acid sequence identity to a chloroplast protein import receptor. FEBS Lett. 557, 109-114.

52 Becker, T., Hritz, J., Vogel, M., Caliebe, A., Bukau, B., Soll, J. and Schleiff, E. (2004). Toc12, a novel subunit of the intermembrane space preprotein translocon of chloroplasts. Mol. Biol. Cell 15, 5130-5144.

53 Perry, S.E. and Keegstra, K. (1994). Envelope membraneproteins that interact with chloroplastic precursor proteins. Plant Cell 6, 93-105.

54 Kouranov, A. and Schnell, D.J. (1997). Analysis of the interactions of preproteins with the import machinery over the course of protein import into chloroplasts. J. Cell Biol. 139, $1677-1685$.

55 Kessler, F., Blobel, G., Patel, H.A. and Schnell, D.J. (1994). Identification of 2 GTP-binding proteins in the chloroplast protein import machinery. Science 266, 1035-1039.

56 Inoue, H. and Akita, M. (2008). Three sets of translocation intermediates are formed during the early stage of protein import into chloroplasts. J. Biol. Chem. 283, 7491-7502. 
57 Pain, D. and Blobel, G. (1987). Protein import into chloroplasts requires a chloroplast ATPase. Proc. Natl. Acad. Sci. U. S. A. 84, 3288-3292.

58 Theg, S.M., Bauerles, C., Olsen, L.J., Selman, B.R. and Keegstra, K. (1989). Internal ATP is the only energy requirement for the translocation of precursor proteins across chloroplastic membranes. J. Biol. Chem. 264, 6730-6736.

59 Hiltbrunner, A., Bauer, J., Vidi, P.A., Infanger, S., Weibel, P., Hohwy, M. and Kessler, F. (2001). Targeting of an abundant cytosolic form of the protein import receptor at Toc159 to the outer chloroplast membrane. J. Cell Biol. 154, 309-316.

60 Bauer, J., Hiltbrunner, A., Weibel, P., Vidi, P.A., AlvarezHuerta, M., Smith, M.D., Schnell, D.J. and Kessler, F. (2002). Essential role of the G-domain in targeting of the protein import receptor atToc159 to the chloroplast outer membrane. J. Cell Biol. 159, 845-854.

61 Smith, M.D., Rounds, C.M., Wang, F., Chen, K.H., Afitlhile, M. and Schnell, D.J. (2004). AtToc159 is a selective transit peptide receptor for the import of nucleus-encoded chloroplast proteins. J. Cell Biol. 165, 323-334.

62 Schnell, D.J., Kessler, F. and Blobel, G. (1994). Isolation of components of the chloroplast protein import machinery. Science 266, 1007-1012.

63 Hirsch, S., Muckel, E., Heemeyer, F., Vonheijne, G. and Soll, J. (1994). A receptor component of the chloroplast protein translocation machinery. Science 266, 1989-1992.

64 Ma, Y.K., Kouranov, A., LaSala, S.E. and Schnell, D.J. (1996). Two components of the chloroplast protein import apparatus, IAP86 and IAP75, interact with the transit sequence during the recognition and translocation of precursor proteins at the outer envelope. J. Cell Biol. 134, 315-327.

65 Sveshnikova, N., Soll, J. and Schleiff, E. (2000). Toc34 is a preprotein receptor regulated by GTP and phosphorylation. Proc. Natl. Acad. Sci. U. S. A. 97, 4973-4978.

66 Schleiff, E., Jelic, M. and Soll, J. (2003). A GTP-driven motor moves proteins across the outer envelope of chloroplasts. Proc. Natl. Acad. Sci. U. S. A. 100, 4604-4609.

67 Becker, T., Jelic, M., Vojta, A., Radunz, A., Soll, J. and Schleiff, E. (2004). Preprotein recognition by the Toc complex. EMBO J. 23, 520-530.

68 Schleiff, E., Soll, J., Kuchler, M., Kuhlbrandt, W. and Harrer, R. (2003). Characterization of the translocon of the outer envelope of chloroplasts. J. Cell Biol. 160, 541-551.

69 Schleiff, E., Soll, J., Sveshnikova, N., Tien, R., Wright, S., Dabney-Smith, C., Subramanian, C. and Bruce, B.D. (2002) Structural and guanosine triphosphate/diphosphate requirements for transit peptide recognition by the cytosolic domain of the chloroplast outer envelope receptor, Toc34. Biochemistry (Mosc.) 41, 1934-1946.

70 Chen, K.H., Chen, X.J. and Schnell, D.J. (2000). Initial binding of preproteins involving the Toc159 receptor can be bypassed during protein import into chloroplasts. Plant Physiol. 122, 813-822

71 Lee, K.H., Kim, S.J., Lee, Y.J., Jin, J.B. and Hwang, I. (2003). The $\mathrm{M}$ domain of atToc159 plays an essential role in the import of proteins into chloroplasts and chloroplast biogenesis. J. Biol. Chem. 278, 36794-36805.

72 Wang, F., Agne, B., Kessler, F. and Schnell, D.J. (2008). The role of GTP binding and hydrolysis at the atToc 159 preprotein receptor during protein import into chloroplasts. J. Cell Biol. 183, 87-99.

73 Stengel, A., Soll, J. and Bolter, B. (2007). Protein import into chloroplasts: new aspects of a well-known topic. Biol. Chem. 388, 765-772.

74 Teng, Y.S., Su, Y.S., Chen, L.J., Lee, Y.J., Hwang, I. and Li, H.M. (2006). Tic21 is an essential translocon component for protein translocation across the chloroplast inner envelope membrane. Plant Cell 18, 2247-2257.

75 Duy, D., Wanner, G., Meda, A.R., von Wiren, N., Soll, J. and Philippar, K. (2007). PIC1, an ancient permease in Arabidopsis chloroplasts, mediates iron transport. Plant Cell 19, 986-1006.
76 Inaba, T., Alvarez-Huerta, M., Li, M., Bauer, J., Ewers, C., Kessler, F. and Schnell, D.J. (2005). Arabidopsis Tic110 is essential for the assembly and function of the protein import machinery of plastids. Plant Cell 17, 1482-1496.

77 Lubeck, J., Soll, J., Akita, M., Nielsen, E. and Keegstra, K. (1996). Topology of IEP110, a component of the chloroplastic protein import machinery present in the inner envelope membrane. EMBO J. 15, 4230-4238.

78 Kessler, F. and Blobel, G. (1996). Interaction of the protein import and folding machineries in the chloroplast. Proc. Natl. Acad. Sci. U. S. A. 93, 7684-7689.

79 Inaba, T., Li, M., Alvarez-Huerta, M., Kessler, F. and Schnell, D.J. (2003). AtTic110 functions as a scaffold for coordinating the stromal events of protein import into chloroplasts. J. Biol. Chem. 278, 38617-38627.

80 Jackson, D.T., Froehlich, J.E. and Keegstra, K. (1998). The hydrophilic domain of Tic110, an inner envelope membrane component of the chloroplastic protein translocation apparatus, faces the stromal compartment. J. Biol. Chem. 273, $16583-16588$.

81 Heins, L., Mehrle, A., Hemmler, R., Wagner, R., Kuchler, M. Hormann, F., Sveshnikov, D. and Soll, J. (2002). The preprotein conducting channel at the inner envelope membrane of plastids. EMBO J. 21, 2616-2625.

82 Balsera, M., Goetze, T., Kovács-Bogdán, E., Schürmann, P., Wagner, R., Buchanan, B., Soll, J. and Bölter, B. (2008). Characterization of Tic110, a channel-forming protein at the inner envelope membrane of chloroplasts, unveils a response to $\mathrm{Ca}^{2+}$ and a stromal regulatory disulfide bridge. J. Biol. Chem. epub Nov 5

83 Stahl, T., Glockmann, C., Soll, J. and Heins, L. (1999). Tic40, a new "old" subunit of the chloroplast protein import translocon. J. Biol. Chem. 274, 37467-37472.

84 Chou, M.L., Fitzpatrick, L.M., Tu, S.L., Budziszewski, G., Potter-Lewis, S., Akita, M., Levin, J.Z., Keegstra, K. and Li, H.M. (2003). Tic40, a membrane-anchored co-chaperone homolog in the chloroplast protein translocon. EMBO J. 22, 2970-2980.

85 Bedard, J., Kubis, S., Bimanadham, S. and Jarvis, P. (2007) Functional similarity between the chloroplast translocon component, Tic40, and the human co-chaperone, Hsp70interacting protein (Hip). J. Biol. Chem. 282, 21404-21414.

86 Nielsen, E., Akita, M., DavilaAponte, J. and Keegstra, K. (1997). Stable association of chloroplastic precursors with protein translocation complexes that contain proteins from both envelope membranes and a stromal Hsp 100 molecular chaperone. EMBO J. 16, 935-946.

87 Constan, D., Froehlich, J.E., Rangarajan, S. and Keegstra, K (2004). A stromal Hsp100 protein is required for normal chloroplast development and function in Arabidopsis. Plant Physiol. 136, 3605-3615.

88 Kouranov, A., Chen, X.J., Fuks, B. and Schnell, D.J. (1998) Tic20 and Tic22 are new components of the protein import apparatus at the chloroplast inner envelope membrane. J. Cell Biol. 143, 991-1002.

89 Caliebe, A., Grimm, R., Kaiser, G., Lubeck, J., Soll, J. and Heins, L. (1997). The chloroplastic protein import machinery contains a Rieske-type iron-sulfur cluster and a mononuclear iron-binding protein. EMBO J. 16, 7342-7350.

90 Kuchler, M., Decker, S., Hormann, F., Soll, J. and Heins, L. (2002). Protein import into chloroplasts involves redoxregulated proteins. EMBO J. 21, 6136-6145.

91 Stengel, A., Benz, P., Balsera, M., Soll, J. and Bolter, B. (2008). TIC62 redox-regulated translocon composition and dynamics. J. Biol. Chem. 283, 6656-6667.

92 Balsera, M., Stengel, A., Soll, J. and Bolter, B. (2007). Tic62: a protein family from metabolism to protein translocation. BMC Evol. Biol. 7, 43.

93 Hormann, F., Kuchler, M., Sveshnikov, D., Oppermann, U., Li, Y. and Soll, J. (2004). Tic32, an essential component in chloroplast biogenesis. J. Biol. Chem. 279, 34756-34762. 
94 Chen, X.J., Smith, M.D., Fitzpatrick, L. and Schnell, D.J. (2002). In vivo analysis of the role of atTic20 in protein import into chloroplasts. Plant Cell 14, 641-654.

95 Rassow, J., Dekker, P.J.T., van Wilpe, S., Meijer, M. and Soll, J. (1999). The preprotein translocase of the mitochondrial inner membrane: Function and evolution. J. Mol. Biol. 286, $105-$ 120.

96 van Dooren, G.G., Tomova, C., Agrawal, S., Humbel, B.M. and Striepen, B. (2008). Toxoplasma gondii Tic20 is essential for apicoplast protein import. Proc. Natl. Acad. Sci. U. S. A. $105,13574-9$.

97 Vojta, A., Alavi, M., Becker, T., Hormann, F., Kuchler, M., Soll, J., Thomson, R. and Schleiff, E. (2004). The protein translocon of the plastid envelopes. J. Biol. Chem. 279, 2140121405.

98 Schnell, D.J. and Blobel, G. (1993). Identification of intermediates in the pathway of protein import into chloroplasts and their localization to envelope contact sites. J. Cell Biol. $120,103-115$.

99 Kovacheva, S., Bedard, J., Patel, R., Dudley, P., Twell, D., Rios, G., Koncz, C. and Jarvis, P. (2005). In vivo studies on the roles of Tic110, Tic40 and Hsp93 during chloroplast protein import. Plant J. 41, 412-428.

100 Chou, M.L., Chu, C.C., Chen, L.J., Akita, M. and Li, H.M. (2006). Stimulation of transit-peptide release and ATP hydrolysis by a cochaperone during protein import into chloroplasts. J. Cell Biol. 175, 893-900.

101 Chiu, C.C. and Min Li, H. (2008). Tic40 is important for reinsertion of proteins from the chloroplast stroma into the inner membrane. Plant J. 56, 793-801.

102 Kovacheva, S., Bedard, J., Wardle, A., Patel, R. and Jarvis, P. (2007). Further in vivo studies on the role of the molecular chaperone, Hsp93, in plastid protein import. Plant J. 50, $364-$ 379.

103 Hirohashi, T., Hase, T. and Nakai, M. (2001). Maize nonphotosynthetic ferredoxin precursor is mis-sorted to the intermembrane space of chloroplasts in the presence of light. Plant Physiol. 125, 2154-2163.

104 Chigri, F., Hormann, F., Stamp, A., Stammers, D.K., Bolter, B., Soll, J. and Vothknecht, U.C. (2006). Calcium regulation of chloroplast protein translocation is mediated by calmodulin binding to Tic32. Proc. Natl. Acad. Sci. U. S. A. 103, $16051-$ 16056

105 Bartsch, S., Monnet, J., Selbach, K., Quigley, F., Gray, J., von Wettstein, D., Reinbothe, S. and Reinbothe, C. (2008). Three thioredoxin targets in the inner envelope membrane of chloroplasts function in protein import and chlorophyll metabolism. Proc. Natl. Acad. Sci. U. S. A. 105, 4933-4938.

106 Chigri, F., Soll, J. and Vothknecht, U.C. (2005). Calcium regulation of chloroplast protein import. Plant J. 42, 821-831.

107 Hofmann, N.R. and Theg, S.M. (2005). Chloroplast outer membrane protein targeting and insertion. Trends in Plant Science 10, 450-457.

108 Hofmann, N.R. and Theg, S.M. (2005). Protein- and energymediated targeting of chloroplast outer envelope membrane proteins. Plant J. 44, 917-927.

109 Tu, S.L. and Li, H.M. (2000). Insertion of OEP14 into the outer envelope membrane is mediated by proteinaceous components of chloroplasts. Plant Cell 12, 1951-1959.

110 Tsai, L.Y., Tu, S.L. and Li, H.M. (1999). Insertion of atToc34 into the chloroplastic outer membrane is assisted by at least two proteinaceous components in the import system. J. Biol. Chem. 274, 18735-18740.

111 Tu, S.L., Chen, L.J., Smith, M.D., Su, Y.S., Schnell, D.J. and Li, H.M. (2004). Import pathways of chloroplast interior proteins and the outer-membrane protein OEP14 converge at Toc75. Plant Cell 16, 2078-2088.

112 Bae, W., Lee, Y.J., Kim, D.H., Lee, J., Kim, S., Sohn, E.J. and Hwang, I. (2008). AKr2A-mediated import of chloroplast outer membrane proteins is essential for chloroplast biogenesis. Nat. Cell Biol. 10, 220-U101.
113 Bedard, J. and Jarvis, P. (2008). Green light for chloroplast outer-membrane proteins. Nat. Cell Biol. 10, 120-122.

114 Bolter, B., Soll, J., Hill, K., Hemmler, R. and Wagner, R. (1999). A rectifying ATP-regulated solute channel in the chloroplastic outer envelope from pea. EMBO J. 18, 55055516.

115 Pohlmeyer, K., Soll, J., Grimm, R., Hill, K. and Wagner, R. (1998). A high-conductance solute channel in the chloroplastic outer envelope from pea. Plant Cell 10, 1207-1216.

116 Tranel, P.J. and Keegstra, K. (1996). A novel, bipartite transit peptide targets OEP75 to the outer membrane of the chloroplastic envelope. Plant Cell 8, 2093-2104.

117 Chan, N.C. and Lithgow, T. (2008). The peripheral membrane subunits of the SAM complex function codependently in mitochondrial outer membrane biogenesis. Mol. Biol. Cell 19, 126-136.

118 Eckart, K., Eichacker, L., Sohrt, K., Schleiff, E., Heins, L. and Soll, J. (2002). A Toc75-like protein import channel is abundant in chloroplasts. EMBO Rep. 3, 557-562.

119 Vojta, L., Soll, J. and Bolter, B. (2007). Protein transport in chloroplasts - targeting to the intermembrane space. FEBS J. $274,5043-5054$.

120 Kouranov, A., Wang, H.A. and Schnell, D.J. (1999). Tic22 is targeted to the intermembrane space of chloroplasts by a novel pathway. J. Biol. Chem. 274, 25181-25186.

121 Brink, S., Fischer, K., Klosgen, R.B. and Flugge, U.I. (1995). Sorting of nuclear-encoded chloroplast membrane-proteins to the envelope and the thylakoid membrane. J. Biol. Chem. 270, 20808-20815

122 Firlej-Kwoka, E., Strittmatter, P., Soll, J. and Bölter, B. (2008). Import of preproteins into the chloroplast inner envelope membrane. Plant Mol. Biol. 68, 505-519.

123 Vojta, L., Soll, J. and Bolter, B. (2007). Requirements for a conservative protein translocation pathway in chloroplasts. FEBS Lett. 581, 2621-2624.

124 Tripp, J., Inoue, K., Keegstra, K. and Froehlich, J.E. (2007). A novel serine/proline-rich domain in combination with a transmembrane domain is required for the insertion of AtTic40 into the inner envelope membrane of chloroplasts. Plant J. 52, 824-838.

125 Kleffmann, T., Russenberger, D., von Zychlinski, A., Christopher, W., Sjolander, K., Gruissem, W. and Baginsky, S. (2004). The Arabidopsis thaliana chloroplast proteome reveals pathway abundance and novel protein functions. Curr. Biol. 14, 354-362.

126 Miras, S., Salvi, D., Ferro, M., Grunwald, D., Garin, J., Joyard, J. and Rolland, N. (2002). Non-canonical transit peptide for import into the chloroplast. J. Biol. Chem. 277, 47770-47778.

127 Nada, A. and Soll, J. (2004). Inner envelope protein 32 is imported into chloroplasts by a novel pathway. J. Cell Sci. 117, 3975-3982.

128 Benning, C., Xu, C.C. and Awai, K. (2006). Non-vesicular and vesicular lipid trafficking involving plastids. Curr. Opin. Plant Biol. 9, 241-247.

129 Villarejo, A., Buren, S., Larsson, S., Dejardin, A., Monne, M., Rudhe, C., Karlsson, J., Jansson, S., Lerouge, P., Rolland, N., von Heijne, G., Grebe, M., Bako, L. and Samuelsson, G. (2005). Evidence for a protein transported through the secretory pathway en route to the higher plant chloroplast. Nat. Cell Biol. 7, 1224-1231.

130 Nanjo, Y., Oka, H., Ikarashi, N., Kaneko, K., Kitajima, A. Mitsui, T., Munoz, F.J., Rodriguez-Lopez, M., Baroja-Fernandez, E. and Pozueta-Romero, J. (2006). Rice plastidial Nglycosylated nucleotide pyrophosphatase/phosphodiesterase is transported from the ER-Golgi to the chloroplast through the secretory pathway. Plant Cell 18, 2582-2592.

131 Schunemann, D. (2007). Mechanisms of protein import into thylakoids of chloroplasts. Biol. Chem. 388, 907-915.

132 Sakamoto, W. (2006). Protein degradation machineries in plastids. Annu. Rev. Plant Biol. 57, 599-621.

133 Weiner, J.H., Bilous, P.T., Shaw, G.M., Lubitz, S.P., Frost, L. Thomas, G.H., Cole, J.A. and Turner, R.J. (1998). A novel and 
ubiquitous system for membrane targeting and secretion of cofactor-containing proteins. Cell 93, 93-101.

134 Braun, N.A., Davis, A.W. and Theg, S.M. (2007). The chloroplast Tat pathway utilizes the transmembrane electric potential as an energy source. Biophys. J. 93, 1993-1998.

135 Braun, N.A. and Theg, S.M. (2008). The chloroplast Tat pathway transports substrates in the dark. J. Biol. Chem. 283, $8822-8828$

136 Cline, K., Ettinger, W.F. and Theg, S.M. (1992). Proteinspecific energy-requirements for protein-transport across or into thylakoid membranes -2 lumenal proteins are transported in the absence of ATP. J. Biol. Chem. 267, 2688-2696.

137 Finazzi, G., Chasen, C., Wollman, F.A. and de Vitry, C. (2003). Thylakoid targeting of Tat passenger proteins shows no Delta $\mathrm{pH}$ dependence in vivo. EMBO J. 22, 807-815.

138 Summer, E.J., Mori, H., Settles, A.M. and Cline, K. (2000). The thylakoid Delta $\mathrm{pH}$-dependent pathway machinery facilitates RR-independent $\mathrm{N}$-tail protein integration. J. Biol. Chem. 275, 23483-23490.

139 Molik, S., Karnauchov, I., Weidlich, C.E., Herrmann, R.G. and Klosgen, R.B. (2001). The Rieske Fe/S protein of the cytochrome $b(6) / f$ complex in chloroplasts - Missing link in the evolution of protein transport pathways in chloroplasts? J. Biol. Chem. 276, 42761-42766.

140 Frielingsdorf, S. and Klosgen, R.B. (2007). Prerequisites for terminal processing of thylakoidal Tat substrates. J. Biol. Chem. 282, 24455-24462.

141 Robinson, C. and Bolhuis, A. (2004). Tat-dependent protein targeting in prokaryotes and chloroplasts. Biochim. Biophys. Acta-Mol. Cell Res. 1694, 135-147.

142 Cline, K. and Mori, H. (2001). Thylakoid Delta pH-dependent precursor proteins bind to a cpTatC-Hcf106 complex before Tha4-dependent transport. J. Cell Biol. 154, 719-729.

143 Dabney-Smith, C., Mori, H. and Cline, K. (2006). Oligomers of Tha4 organize at the thylakoid Tat translocase during protein transport. J. Biol. Chem. 281, 5476-5483.

144 Cline, K. and McCaffery, M. (2007). Evidence for a dynamic and transient pathway through the TAT protein transport machinery. EMBO J. 26, 3039-3049.

145 Gohlke, U., Pullan, L., McDevitt, C., Porcelli, I., de Leeuw, E., Palmer, T., Saibil, H. and Berks, B. (2005). The TatA component of the twin-arginine protein transport system forms channel complexes of variable diameter. Proc. Natl. Acad. Sci. U. S. A. 102, 10482-10486.

146 Veenendaal, A.K.J., van der Does, C. and Driessen, A.M. (2004). The protein-conducting channel SecYEG. Biochim. Biophys. Acta-Mol. Cell Res. 1694, 81-95.

147 Laidler, V., Chaddock, A.M., Knott, T.G., Walker, D. and Robinson, C. (1995). A SecY homolog in Arabidopsis thaliana sequence of a full-length cDNA clone and import of the precursor protein into chloroplasts. J. Biol. Chem. 270, 17664 17667.

148 Schuenemann, D., Amin, P., Hartmann, E. and Hoffman, N.E. (1999). Chloroplast SecY is complexed to SecE and involved in the translocation of the 33-kDa but not the 23-kDa subunit of the oxygen-evolving complex. J. Biol. Chem. 274, $12177-$ 12182.

149 Nakai, M., Goto, A., Nohara, T., Sugita, D. and Endo, T. (1994). Identification of the Seca Protein Homolog in PeaChloroplasts and Its Possible Involvement in Thylakoidal Protein-Transport. J. Biol. Chem. 269, 31338-31341.

150 Yuan, J.G., Henry, R., McCaffery, M. and Cline, K. (1994). SecA homolog in protein-transport within chloroplasts evidence for endosymbiont-derived sorting. Science 266, 796798

151 Karamanou, S., Vrontou, E., Sianidis, G., Baud, C., Roos, T., Kuhn, A., Politou, A.S. and Economou, A. (1999). A molecular switch in SecA protein couples ATP hydrolysis to protein translocation. Mol. Microbiol. 34, 1133-1145.

152 Sun, C., Rusch, S.L., Kim, J. and Kendall, D.A. (2007). Chloroplast SecA and Escherichia coli SecA have distinct lipid and signal peptide. J. Bacteriol. 189, 1171-1175.
153 Keenan, R.J., Freymann, D.M., Stroud, R.M. and Walter, P. (2001). The signal recognition particle. Annu. Rev. Biochem. $70,755-775$.

154 Luirink, J., Samuelsson, T. and de Gier, J.W. (2001). YidC/ Oxa1p/Alb3: evolutionarily conserved mediators of membrane protein assembly. FEBS Lett. 501, 1-5.

155 Schuenemann, D., Gupta, S., Persello-Cartieaux, F., Klimyuk, V.I., Jones, J.D.G., Nussaume, L. and Hoffman, N.E. (1998). A novel signal recognition particle targets lightharvesting proteins to the thylakoid membranes. Proc. Natl. Acad. Sci. U. S. A. 95, 10312-10316.

156 Stengel, K.F., Holdermann, I., Cain, P., Robinson, C., Wild, K. and Sinning, I. (2008). Structural basis for specific substrate recognition by the chloroplast signal recognition particle protein cpSRP43. Science 321, 253-256.

157 Franklin, A.E. and Hoffman, N.E. (1993). Characterization of a chloroplast homolog of the $54-\mathrm{kDa}$ subunit of the signal recognition particle. J. Biol. Chem. 268, 22175-22180.

158 Stengel, K.F., Holdermann, I., Wild, K. and Sinning, I. (2007). The structure of the chloroplast signal recognition particle (SRP) receptor reveals mechanistic details of SRP GTPase activation and a conserved membrane targeting site. FEBS Lett. 581, 5671-5676.

159 Sundberg, E., Slagter, J.G., Fridborg, I., Cleary, S.P., Robinson, C. and Coupland, G. (1997). ALBINO3, an Arabidopsis nuclear gene essential for chloroplast differentiation, encodes a chloroplast protein that shows homology to proteins present in bacterial membranes and yeast mitochondria. Plant Cell 9, 717-730.

160 Powers, T. and Walter, P. (1995). Reciprocal stimulation of GTP hydrolysis by 2 directly interacting GTPases. Science $269,1422-1424$.

161 Jaru-Ampornpan, P., Chandrasekar, S. and Shan, S.O. (2007). Efficient interaction between two GTPases allows the chloroplast SRP pathway to bypass the requirement for an SRP RNA. Mol. Biol. Cell 18, 2636-2645.

162 Schunemann, D. (2004). Structure and function of the chloroplast signal recognition particle. Curr. Genet. 44, $295-$ 304.

163 Nilsson, R. and van Wijk, K.J. (2002). Transient interaction of cpSRP54 with elongating nascent chains of the chloroplastencoded D1 protein; 'cpSRP54 caught in the act'. FEBS Lett. $524,127-133$.

164 Kathir, K.M., Rajalingam, D., Sivaraja, V., Kight, A., Goforth, R.L., Yu, C., Henry, R. and Kumar, T.K.S. (2008). Assembly of chloroplast signal recognition particle involves structural rearrangement in cpSRP43. J. Mol. Biol. 381, 4960.

165 Moore, M., Goforth, R.L., Mori, H. and Henry, R. (2003) Functional interaction of chloroplast SRP/FtsY with the ALB3 translocase in thylakoids: substrate not required. J. Cell Biol. 162, 1245-1254

166 Kogata, N., Nishio, K., Hirohashi, T., Kikuchi, S. and Nakai, M. (1999). Involvement of a chloroplast homologue of the signal recognition particle receptor protein, FtsY, in protein targeting to thylakoids. FEBS Lett. 447, 329-333.

167 Tzvetkova-Chevolleau, T., Hutin, C., Noel, L.D., Goforth, R., Carde, J.P., Caffarri, S., Sinning, I., Groves, M., Teulon, J.M., Hoffman, N.E., Henry, R., Havaux, M. and Nussaume, L. (2007). Canonical signal recognition particle components can be bypassed for posttranslational protein targeting in chloroplasts. Plant Cell 19, 1635-1648.

168 Robinson, D., Karnauchov, I., Herrmann, R.G., Klosgen, R.B. and Robinson, C. (1996). Protease-sensitive thylakoidal import machinery for the Sec-, Delta $\mathrm{pH}$ - and signal recognition particle-dependent protein targeting pathways, but not for CFoII integration. Plant J. 10, 149-155.

169 Tissier, C., Woolhead, C.A. and Robinson, C. (2002). Unique structural determinants in the signal peptides of 'spontaneously' inserting thylakoid membrane proteins. Eur. J. Biochem. 269, 3131-3141. 
170 Thompson, S.J., Kim, S.J. and Robinson, C. (1998). Secindependent insertion of thylakoid membrane proteins Analysis of insertion forces and identification of a loop intermediate involving the signal peptide. J. Biol. Chem. 273, 18979-18983.

171 Neupert, W. and Herrmann, J.M. (2007). Translocation of proteins into mitochondria. Annu. Rev. Biochem. 76, $723-$ 749.

172 Emanuelsson, O., Brunak, S., von Heijne, G. and Nielsen, H. (2007). Locating proteins in the cell using TargetP, SignalP and related tools. Nat. Protoc. 2, 953-971.

173 Hill, K., Model, K., Ryan, M.T., Dietmeier, K., Martin, F., Wagner, R. and Pfanner, N. (1998). Tom40 forms the hydrophilic channel of the mitochondrial import pore for preproteins. Nature 395, 516-521.

174 Schlegel, T., Mirus, O., von Haeseler, A. and Schleiff, E. (2007). The tetratricopeptide repeats of receptors involved in protein translocation across membranes. Mol. Biol. Evol. 24, 2763-2774.

$175 \mathrm{Wu}$, Y.K. and Sha, B.D. (2006). Crystal structure of yeast mitochondrial outer membrane translocon member Tom70p. Nat. Struct. Mol. Biol. 13, 589-593.

176 Brix, J., Dietmeier, K. and Pfanner, N. (1997). Differential recognition of preproteins by the purified cytosolic domains of the mitochondrial import receptors Tom20, Tom22, and Tom70. J. Biol. Chem. 272, 20730-20735.

177 Abe, Y., Shodai, T., Muto, T., Mihara, K., Torii, H., Nishikawa, S., Endo, T. and Kohda, D. (2000). Structural basis of presequence recognition by the mitochondrial protein import receptor Tom20. Cell 100, 551-560.

178 Chan, N.C., Likic, V.A., Waller, R.F., Mulhern, T.D. and Lithgow, T. (2006). The C-terminal TPR domain of Tom70 defines a family of mitochondrial protein import receptors found only in animals and fungi. J. Mol. Biol. 358, 1010-1022.

179 Honlinger, A., Kubrich, M., Moczko, M., Gartner, F., Mallet, L., Bussereau, F., Eckerskorn, C., Lottspeich, F., Dietmeier, K., Jacquet, M. and Pfanner, N. (1995). The mitochondrial receptor complex - Mom22 Is essential for cell viability and directly interacts with preproteins. Mol. Cell. Biol. 15, 33823389.

180 van Wilpe, S., Ryan, M.T., Hill, K., Maarse, A.C., Meisinger, C., Brix, J., Dekker, P.J.T., Moczko, M., Wagner, R., Meijer, M., Guiard, B., Honlinger, A. and Pfanner, N. (1999). Tom22 is a multifunctional organizer of the mitochondrial preprotein translocase. Nature 401, 485-489.

181 Moczko, M., Bomer, U., Kubrich, M., Zufall, N., Honlinger, A. and Pfanner, N. (1997). The intermembrane space domain of mitochondrial Tom 22 functions as a trans binding site for properties with $\mathrm{N}$-terminal targeting sequences. Mol. Cell. Biol. 17, 6574-6584.

182 Chacinska, A., Lind, M., Frazier, A.E., Dudek, J., Meisinger, C., Geissler, A., Sickmann, A., Meyer, H.E., Truscott, K.N., Guiard, B., Pfanner, N. and Rehling, P. (2005). Mitochondrial presequence translocase: Switching between TOM tethering and motor recruitment involves Tim 21 and Tim17. Cell 120, $817-829$

183 Dietmeier, K., Honlinger, A., Bomer, U., Dekker, P.J.T., Eckerskorn, C., Loffspeich, F., Kubrich, M. and Pfanner, N. (1997). Tom5 functionally links mitochondrial preprotein receptors to the general import pore. Nature 388, 195-200.

184 Honlinger, A., Bomer, U., Alconada, A., Eckerskorn, C., Lottspeich, F., Dietmeier, K. and Pfanner, N. (1996). Tom7 modulates the dynamics of the mitochondrial outer membrane translocase and plays a pathway-related role in protein import. EMBO J. 15, 2125-2137.

185 Rapaport, D., Kunkele, K.P., Dembowski, M., Ahting, U., Nargang, F.E., Neupert, W. and Lill, R. (1998). Dynamics of the TOM complex of mitochondria during binding and translocation of preproteins. Mol. Cell. Biol. 18, 5256-5262.

186 Meisinger, C., Ryan, M.T., Hill, K., Model, K., Lim, J.H., Sickmann, A., Muller, H., Meyer, H.E., Wagner, R. and Pfanner, N. (2001). Protein import channel of the outer mitochondrial membrane: a highly stable Tom 40 -Tom 22 core structure differentially interacts with preproteins, small Tom proteins, and import receptors. Mol. Cell. Biol. 21, 2337-2348.

187 Paschen, S.A., Waizenegger, T., Stan, T., Preuss, M., Cyrklaff, M., Hell, K., Rapaport, D. and Neupert, W. (2003). Evolutionary conservation of biogenesis of beta-barrel membrane proteins. Nature $426,862-866$.

188 Waizenegger, T., Habib, S.J., Lech, M., Mokranjac, D., Paschen, S.A., Hell, K., Neupert, W. and Rapaport, D. (2004). Tob38, a novel essential component in the biogenesis of beta-barrel proteins of mitochondria. EMBO Rep. 5, 704709 .

189 Milenkovic, D., Kozjak, V., Wiedemann, N., Lohaus, C., Meyer, H.E., Guiard, B., Pfanner, N. and Meisinger, C. (2004). Sam35 of the mitochondrial protein sorting and assembly machinery is a peripheral outer membrane protein essential for cell viability. J. Biol. Chem. 279, 22781-22785.

190 Wiedemann, N., Kozjak, V., Chacinska, A., Schonfisch, B., Rospert, S., Ryan, M.T., Pfanner, N. and Meisinger, C. (2003). Machinery for protein sorting and assembly in the mitochondrial outer membrane. Nature 424, 565-571.

191 Stojanovski, D., Guiard, B., Kozjak-Pavlovic, V., Pfanner, N. and Meisinger, C. (2007). Alternative function for the mitochondrial SAM complex in biogenesis of alpha-helical TOM proteins. J. Cell Biol. 179, 881-893.

192 Herrmann, J.M. and Hell, K. (2005). Chopped, trapped or tacked-protein translocation into the IMS of mitochondria. Trends Biochem. Sci. 30, 205-211.

193 Mesecke, N., Terziyska, N., Kozany, C., Baumann, F., Neupert, W., Hell, K. and Herrmann, J.M. (2005). A disulfide relay system in the intermembrane space of mitochondria that mediates protein import. Cell 121, 1059-1069.

194 Chacinska, A., Pfannschmidt, S., Wiedemann, N., Kozjak, V., Szklarz, L.K.S., Schulze-Specking, A., Truscott, K.N., Guiard, B., Meisinger, C. and Pfanner, N. (2004). Essential role of Mia40 in import and assembly of mitochondrial intermembrane space proteins. EMBO J. 23, 3735-3746.

195 Leuenberger, D., Bally, N.A., Schatz, G. and Koehler, C.M. (1999). Different import pathways through the mitochondrial intermembrane space for inner membrane proteins. EMBO J. $18,4816-4822$.

196 Webb, C.T., Gorman, M.A., Lazarou, M., Ryan, M.T. and Gulbis, J.M. (2006). Crystal structure of the mitochondrial chaperone TIM9 center dot 10 reveals a six-bladed alphapropeller. Mol. Cell 21, 123-133.

197 Lu, H., Golovanov, A.P., Alcock, F., Grossmann, J.G., Allen, S., Lian, L.Y. and Tokatlidis, K. (2004). The structural basis of the TIM10 chaperone assembly. J. Biol. Chem. 279, 1895918966.

198 Hell, K., Herrmann, J.M., Pratje, E., Neupert, W. and Stuart, R.A. (1998). Oxa1p, an essential component of the N-tail protein export machinery in mitochondria. Proc. Natl. Acad. Sci. U. S. A. 95, 2250-2255.

199 Bauer, M.F., Sirrenberg, C., Neupert, W. and Brunner, M. (1996). Role of Tim23 as voltage sensor and presequence receptor in protein import into mitochondria. Cell 87, 33-41.

200 Meier, S., Neupert, W. and Herrmann, J.M. (2005). Conserved $\mathrm{N}$-terminal negative charges in the Tim17 subunit of the TIM23 translocase play a critical role in the import of preproteins into mitochondria. J. Biol. Chem. 280, 7777-7785.

201 Donzeau, M., Kaldi, K., Adam, A., Paschen, S., Wanner, G., Guiard, B., Bauer, M.F., Neupert, W. and Brunner, M. (2000). Tim23 links the inner and outer mitochondrial membranes. Cell 101, 401-412.

202 Mokranjac, D., Paschen, S.A., Kozany, C., Prokisch, H., Hoppins, S.C., Nargang, F.E., Neupert, W. and Hell, K. (2003). Tim50, a novel component of the TIM23 preprotein translocase of mitochondria. EMBO J. 22, 816-825.

203 Berthold, J., Bauer, M.F., Schneider, H.C., Klaus, C. Dietmeier, K., Neupert, W. and Brunner, M. (1995). The Mim complex mediates preprotein translocation across the 
mitochondrial inner membrane and couples it to the MtHsp70/ATP driving system. Cell 81, 1085-1093.

204 Mokranjac, D., Sichting, M., Neupert, W. and Hell, K. (2003). Tim14, a novel key component of the import motor of the TIM23 protein translocase of mitochondria. EMBO J. 22, $4945-4956$.

205 Kozany, C., Mokranjac, D., Sichting, M., Neupert, W. and Hell, K. (2004). The J domain-related cochaperone Tim16 is a constituent of the mitochondrial TIM23 preprotein translocase. Nat. Struct. Mol. Biol. 11, 234-241.

206 Okamoto, K., Brinker, A., Paschen, S.A., Moarefi, I., HayerHartl, M., Neupert, W. and Brunner, M. (2002). The protein import motor of mitochondria: a targeted molecular ratchet driving unfolding and translocation. EMBO J. 21, 3659-3671.

207 Neupert, W. and Brunner, M. (2002). The protein import motor of mitochondria. Nat. Rev. Mol. Cell Biol. 3, 555-565.

208 Wiedemann, N., van der Laan, M., Hutu, D., Rehling, P. and Pfanner, N. (2007). Sorting switch of mitochondrial presequence translocase involves coupling of motor module to respiratory chain. J. Cell Biol. 179, 1115-1122.

209 Popov-Celeketic, D., Mapa, K., Neupert, W. and Mokranjac, D. (2008). Active remodelling of the TIM23 complex during translocation of preproteins into mitochondria. EMBO J. 27, $1469-1480$

210 Koehler, C.M., Jarosch, E., Tokatlidis, K., Schmid, K., Schweyen, R.J. and Schatz, G. (1998). Import of mitochondrial carriers mediated by essential proteins of the intermembrane space. Science 279, 369-373.

211 Kovermann, P., Truscott, K.N., Guiard, B., Rehling, P., Sepuri, N.B., Muller, H., Jensen, R.E., Wagner, R. and Pfanner, N. (2002). Tim22, the essential core of the mitochondrial protein insertion complex, forms a voltage-activated and signal-gated channel. Mol. Cell 9, 363-373.

212 Wagner, K., Gebert, N., Guiard, B., Brandner, K., Truscott, K.N., Wiedemann, N., Pfanner, N. and Rehling, P. (2008). The assembly pathway of the mitochondrial carrier translocase involves four preprotein translocases. Mol. Cell. Biol. 28, $4251-4260$

213 Rehling, P., Brandner, K. and Pfanner, N. (2004). Mitochondrial import and the twin-pore translocase. Nat. Rev. Mol. Cell Biol. 5, 519-530.

214 Lister, R. and Whelan, J. (2006). Mitochondrial protein import: Convergent solutions for receptor structure. Curr. Biol. 16, R197-R199.
215 Macasev, D., Newbigin, E., Whelan, J. and Lithgow, T. (2000). How do plant mitochondria avoid importing chloroplast proteins? Components of the import apparatus Tom 20 and Tom 22 from Arabidopsis differ from their fungal counterparts. Plant Physiol. 123, 811-816.

216 Lister, R., Chew, O., Lee, M.N., Heazlewood, J.L., Clifton, R., Parker, K.L., Millar, A.H. and Whelan, J. (2004). A transcriptomic and proteomic characterization of the Arabidopsis mitochondrial protein import apparatus and its response to mitochondrial dysfunction. Plant Physiol. 134, 777-789.

217 Figueroa-Martinez, F., Funes, S., Franzen, L.G. and Gonzalez-Halphen, D. (2008). Reconstructing the mitochondrial protein import machinery of Chlamydomonas reinhardtii. Genetics 179, 149-155.

218 Perry, A.J., Hulett, J.M., Likic, V.A., Lithgow, T. and Gooley, P.R. (2006). Convergent evolution of receptors for protein import into mitochondria. Curr. Biol. 16, 221-229.

219 Werhahn, W., Jansch, L. and Braun, H.P. (2003). Identification of novel subunits of the TOM complex from Arabidopsis thaliana. Plant Physiol. Biochem. 41, 407-416.

220 Murcha, M.W., Lister, R., Ho, A.Y.Y. and Whelan, J. (2003). Identification, expression, and import of components 17 and 23 of the inner mitochondrial membrane translocase from Arabidopsis. Plant Physiol. 131, 1737-1747.

221 Sakamoto, W., Spielewoy, N., Bonnard, G., Murata, M. and Wintz, H. (2000). Mitochondrial localization of AtOXA1, an Arabidopsis homologue of yeast Oxalp involved in the insertion and assembly of protein complexes in mitochondrial inner membrane. Plant Cell Physiol. 41, 1157-1163.

222 Pujol, C., Marechal-Drouard, L. and Duchene, A.M. (2007). How can organellar protein $\mathrm{N}$-terminal sequences be dual targeting signals? In silico analysis and mutagenesis approach. J. Mol. Biol. 369, 356-367.

223 Chew, O., Rudhe, C., Glaser, E. and Whelan, J. (2003). Characterization of the targeting signal of dual-targeted pea glutathione reductase. Plant Mol. Biol. 53, 341-356.

224 Chew, O. and Whelan, J. (2004). Just read the message: a model for sorting of proteins between mitochondria and chloroplasts. Trends in Plant Science 9, 318-319.

225 Chew, O. and Whelan, J. (2003). Dual targeting ability of targeting signals is dependent on the nature of the mature protein. Funct. Plant Biol. 30, 805-812.

\section{To access this journal online: http://www.birkhauser.ch/CMLS}

